\title{
La reforma energética y el problema petrolero en México *
}

The Energy Reform and the Oil Problem in Mexico

\author{
Bruno Sovilla (iD) \\ Doctor en Política Económica, Universidad Autónoma de Chiapas, \\ San Cristóbal de las Casas-México, bruno.sovilla@unach.mx \\ Eusebio Gómez-Ramírez \\ Licenciado en Economía (pasante), Universidad Autónoma de Chiapas, \\ Nuevo Limar-México, eugomezr96@gmail.com \\ Manuel Sánchez-Pérez \\ Licenciado en Economía (pasante), Universidad Autónoma de Chiapas, \\ Chilón-México, mansanchez95@gmail.com
}

Cómo citar / How to cite

Sovilla, B.; Gómez-Ramírez, E.; Sánchez-Pérez, M. (2021). La reforma energética y el problema petrolero en México. Revista CEA, v. 7, n. 13, e1631. https://doi.org/10.22430/24223182.1631

Recibido: 28 de junio de 2020

Aceptado: 14 de septiembre de 2020

\section{Resumen}

Desde la expropiación petrolera, y durante varias décadas, Petróleos Mexicanos (PEMEX) venía soportando el despegue del sector industrial. Así, a partir de los años 70 ha cumplido principalmente con dos funciones: generar divisa y contribuir en la financiación del gasto público a través del pago de impuestos. Hoy, sin embargo, la empresa petrolera enfrenta una crisis profunda. El objetivo de este trabajo es aclarar cómo se produjo la actual crisis energética por la que atraviesa el país, e indicar otros posibles caminos para afrontarla. Utilizando datos oficiales del Instituto Nacional de Estadística y Geografía y de PEMEX se encuentra que en las últimas décadas las finanzas públicas han dependido, en gran medida, de los ingresos petroleros y, como consecuencia, PEMEX no ha podido llevar a cabo los proyectos de inversión necesarios para mantener o incrementar la producción. Como resultado, se ha exacerbado el declive de la producción, lo que ha creado las condiciones para la reforma energética a fin de atraer la inversión privada en este sector. Se concluye que una posible alternativa para evitar la privatización de un recurso natural tan estratégico como el petróleo sería aprobar una

\footnotetext{
* Este artículo se deriva del proyecto titulado «La reforma energética y el problema petrolero en México» y ha sido financiado con recursos propios.
} 
reforma fiscal que aumente los ingresos tributarios no petroleros, permitiéndole a PEMEX financiar la inversión necesaria para contrarrestar la caída de la producción.

Palabras clave: crisis energética, economía de la energía, recursos energéticos, industria del petróleo, economía mexicana.

Clasificación JEL: Q40, Q43.

\begin{abstract}
After the Mexican oil expropriation, Petróleos Mexicanos (PEMEX) initially experienced the take-off of the industrial sector; but, since the 1970s, the company has mainly served two purposes: to make a profit and to contribute to fund government spending through taxes. Today, this oil company is facing a deep crisis. The aim of this study is to shed light on the origins of the current energy crisis of the country and propose different possibilities to address it. Using official data provided by the INEGI and PEMEX, we found that, in recent decades, the public finances in Mexico have greatly depended on oil revenue and, as a consequence, PEMEX has not been able to carry out the investment projects needed to maintain or increase their production. This has contributed to further the production decline, creating the right circumstances for an energy reform that attracts private investors to this sector. We conclude that a possible alternative to avoid the privatization of such a strategic natural resource as oil is passing a tax reform that increases non-oil-related tax revenue, thus enabling PEMEX to fund the investments needed to tackle the production decline.
\end{abstract}

Keywords: Energy crisis, energy economy, energy resources, oil industry, Mexican economy.

JEL classification: Q40, Q43.

\title{
1. INTRODUCCIÓN
}

El 18 de marzo de 1938, el presidente Lázaro Cárdenas procedió a la expropiación de la industria petrolera en México. Desde entonces, y durante todos estos años, la empresa petrolera paraestatal, PEMEX, ha asumido una importante función dentro de la economía nacional, extrayendo el petróleo que utiliza la industria, abasteciendo oportunamente la demanda interna de combustibles para uso familiar, generando divisas y asegurando una parte importante de la recaudación tributaria. En una perspectiva internacional, en 2018 México ocupaba el lugar 12 en producción de petróleo crudo, y el lugar 17 en producción de gas natural. Mientras que, en 2017, dentro de la lista de las principales empresas energéticas, ya fueran públicas o privadas, la petrolera estatal ocupó el lugar 11 en cuanto a producción de petróleo crudo; en producción de gas natural, el lugar 16; y, en ventas totales, el lugar 18 (PEMEX, 2018).

Desde su creación, PEMEX ha dominado la industria petrolera, constituido en un monopolio al cual se asignó, por mandato constitucional, el control total de la extracción y comercialización de los hidrocarburos. En 1997, considerando que la inversión de la paraestatal no era suficiente, el Gobierno permitió la participación limitada de empresas privadas en el sector energético, según el esquema de los Proyectos de Inversión Diferidos en el Gasto (PIDIREGAS), sin tener que modificar la Constitución. Sin embargo, desde hace una década, desde el año 2005, PEMEX enfrenta una situación muy 
complicada: el agotamiento de los mega yacimientos petroleros, como el complejo Cantarell, y la baja inversión productiva, lo cual trae, como consecuencia, el declive de la producción que ha determinado, por primera vez en la historia reciente del país, una balanza energética deficitaria, algo anómalo para un país petrolero, que pone en riesgo su autosuficiencia energética. Esta situación ha originado la reforma energética (RE) que contempla la participación del sector privado (también del capital extranjero) en la industria petrolera para realizar actividades que antes solo eran exclusivas de PEMEX.

Padilla y Wood (2018, p. 5) consideran la reforma un éxito, e invocan «decisiones difíciles pero necesarias con respecto a Pemex». Los mismos autores subrayan el nivel de endeudamiento de la empresa petrolera, más de un tercio de la deuda pública en 2017, y reconocen su baja inversión, pero la atribuyen a la caída del precio del petróleo que ha mermado sus ingresos. Hacen también hincapié en los altos niveles de corrupción en la empresa estatal y el elevado gasto corriente, sobre todo en pensiones. Por el contrario, otro especialista reconoce «el origen de los problemas financieros de PEMEX» en la voluntad de la Secretaría de Hacienda y Crédito Público (SHCP) de "controlar el excedente de caja de PEMEX a fin de mitigar las presiones sobre el balance fiscal» (Alejo, 2014, p. 11).

Por nuestra parte, nosotros también pensamos que el régimen fiscal al que PEMEX ha estado sujeto, a través del pago de impuestos y derechos ha resultado ser una carga muy pesada que, a la larga, ha mermado su potencial productivo. Por eso, proponemos una reforma fiscal que aumente los ingresos tributarios no petroleros y libere a PEMEX de sus excesivas obligaciones tributarias sin comprometer las finanzas públicas, lo que le permitiría realizar las inversiones necesarias en el sector petrolero nacional para recuperar los niveles de producción deseables.

\section{MARCO TEÓRICO}

\section{El monopolio natural}

La actividad petrolera tiene las condiciones a nivel microeconómico que la caracterizan como monopolio natural (Hammoudeh et al., 2013). Se trata de una situación conocida como un fallo del mercado (Greene \& Liu, 2015; Stiglitz, 2000), en la cual la competencia entre productores no asegura la reducción del precio hasta el nivel de los costos unitarios. Esto se genera en los sectores donde hay economías de escala, o sea, reducciones continuas de los costos unitarios, aumentando los niveles de producción (Huang, 2002). Dados los altos costos fijos iniciales, la curva del costo medio (Cme) no tiene la clásica forma de «U» y es decreciente, acercándose asintóticamente al costo marginal (Cmg) que, para simplificar el razonamiento, podemos considerar constante. Esto significa que, para poder producir con costos unitarios bajos, un solo productor debe satisfacer toda la demanda, por tanto, una situación competitiva donde el mercado se reparte entre varias empresas, afectaría a los consumidores, porque cada productor tendría altos costos unitarios y se aplicarían precios elevados.

En esta situación, si el mercado se subdivide entre varios productores, sus niveles de producción no les permitirá aprovechar las economías de escala. Por tanto, la solución competitiva no conviene, pues las empresas tendrían niveles de producción bajos, aplicando precios más altos que el costo mínimo unitario. La única manera para poder lograr un precio bajo es que un solo productor satisfaga 
toda la demanda, aprovechando las economías de escala. La misma teoría convencional (neoclásica) llega a la conclusión de que la creación de grandes empresas públicas en el sector energético, así como sucesivamente en las telecomunicaciones y los sectores donde hay economías de escala, no fue solo el reflejo de la difusión de las ideas keynesianas sobre el papel del Estado en la regulación de una economía de mercado, pues también tenía una clara justificación en la teoría microeconómica (Sorin, 2019).

Sin embargo, como se ha visto (Padilla y Wood, 2018), el debate energético en México ha privilegiado otras vertientes (Fry, 2018). En lugar de generar una discusión sobre una posible transición hacia la utilización de fuentes energéticas alternativas a los combustibles fósiles y renovables, este "es sin duda el más importante elemento ausente en la reforma» (Aguilera et al., 2016, p. 44). La RE podría ser una ocasión para abrir una discusión sobre el futuro de la industria petrolera en México, pues sabemos que los depósitos de gas y petróleo en el norte del país son de lutitas y a grandes profundidades, y en el Golfo de México en aguas profundas. Ambos implican altos costos de extracción, lo cual, en un contexto de reducción de los precios del petróleo, legitima dudas sobre su conveniencia económica.

Pero, el Gobierno de Peña Nieto cargó su propuesta con argumentos muy ideológicos, enfatizando los bajos niveles de eficiencia de la empresa pública, la corrupción de sus altos mandos y de los máximos dirigentes sindicales, los generosos tratos a trabajadores y pensionados que han creado en PEMEX un flujo creciente de gastos corrientes, como si este proceso degenerativo hubiese estado ajeno al contubernio con la acción política de los gobiernos panistas y priistas de las últimas décadas. Sin embargo, un examen más atento de la situación financiera de la petrolera estatal muestra que, a pesar de la corrupción de sus altos dirigentes y de los líderes sindicales, PEMEX

se ha ubicado como una de las primeras petroleras del mundo en la generación de utilidades brutas y desde 1998, con excepción de 2006 y 2012, los montos que paga al fisco superan sistemáticamente su rendimiento o utilidad de operación, después de cubrir los costos financieros. (Aguilera et al., 2016, p. 18)

Para el mes de agosto de 2020, el exdirector de Pemex (2012-2016), Emilio Lozoya Austin, acababa de ser extraditado de España y se encontraba en México acusado de corrupción. Romero Deschamps, secretario general del sindicato de trabajadores petroleros desde 1993 hasta 2019, en 2013 había sido declarado por la revista Forbes como la segunda persona más corrupta de México y actualmente está prófugo de la justicia.

Varios autores aclaran que PEMEX «no puede funcionar como empresa, por restricciones operativas, financiarías y presupuestarias» (Barnés de Castro, 2013), concepto compartido por Aguilera et al., (2016, p. 42): «la carga fiscal de PEMEX (...) sigue siendo sumamente gravosa (...) también en comparación con las principales empresas internacionales y entidades estatales en su ramo». Según Padilla y Wood $(2018$, p. 7) el problema fiscal en Pemex es que «parte de la recaudación fiscal sea cobrada directamente por los municipios...», afirmación que desvía la atención hacia otro tipo de problema, que se ha discutido en otros trabajos (Sovilla et al., 2018). La descentralización fiscal en México no ha sido exitosa y ha contribuido a aumentar la corrupción, como lo demuestra la cantidad de gobernadores y exgobernadores encarcelados en los últimos años. 
Es curioso que los autores citados evidencien, por un lado, la corrupción en PEMEX como factor que justifica la apertura al capital extranjero, y que, por otro, propongan mecanismos que la han propiciado, como fue la descentralización del gasto público a nivel estatal y municipal sin que se acompañara con una descentralización de la recaudación (como sería también en este caso, si PEMEX entregara, como ellos proponen, parte de sus ingresos directamente a los municipios y no al Gobierno federal). Además, habría un aumento de la desigualdad territorial, puesto que algunos municipios recibirían ingresos de PEMEX y otros no, según tengan yacimientos de petróleo en su territorio o no, algo que no es recomendable en la situación actual.

De acuerdo con Alejo (2014, p. 10), quien fue secretario de Patrimonio Nacional y como tal presidente del Consejo de Administración de PEMEX y de la Comisión Federal de Electricidad (CFE) «el origen de la problemática financiera de PEMEX» es la voluntad de la SHCP de «controlar el excedente de caja de PEMEX a fin de mitigar las presiones sobre el balance fiscal». El mismo autor informa que en 1974 la SHCP y la Secretaría de Patrimonio Nacional acordaron aplicar «un esquema de acciones de carácter temporal, sujeto a la condición que la SHCP sufragaría los requerimientos de inversión de PEMEX». Sin embargo, según el especialista, la sujeción de PEMEX a la SHCP había empezado una década antes, siendo secretario de hacienda Ortiz Mena, y se ha mantenido hasta años recientes, con el resultado de que el Gobierno mexicano ha captado entre el $93.9 \%$ y el $99 \%$ de sus excedentes de operación (conversación con Alejo y Ortiz Mena, citado en Alejo, 2014, p. 10).

Cabe recordar que en 1961 el mismo secretario de hacienda, Ortiz Mena, había encargado al economista N. Kaldor una propuesta de reforma fiscal Aboites Aguilar y Unda Gutiérrez (2011), para modernizar el sistema tributario mexicano, caracterizado por un marcado sesgo regresivo y una baja recaudación. La propuesta elaborada por Kaldor fue rechazada por la elite económica de la época, que se veía perjudicada por tener que pagar los impuestos que se aplicaban en los países más avanzados y que, dicho sea de paso, permitieron en esa década en Europa avanzar hacia la creación del estado social, gracias al cual muchos países tienen hoy día un sistema de salud pública universal, algo valioso en las circunstancias que estamos viviendo.

Es evidente que, frente a las resistencias encontradas entre la élite más acomodada, la administración del presidente López Mateos escogió el camino más fácil: evitar aplicar la reforma Kaldor y, a través de PEMEX, lograr el incremento de la recaudación tributaria para poder financiar los niveles de gasto público considerados necesarios.

\section{METODOLOGÍA}

Para realizar este trabajo se han consultado bases de datos y se ha hecho una revisión de la literatura respecto al tema energético. Durante la primera fase de la investigación se consultaron las bases de datos existentes de fuentes oficiales como INEGI y PEMEX, considerando que el objetivo principal es encontrar indicadores que permitan entender $y$, sobre todo, aclarar las condiciones de la empresa petrolera mexicana previas a la reforma energética de 2013. La mayoría de los datos que se tomaron en cuenta están constituidos a través de series de tiempo que comprenden el periodo 1993-2019 y otros de 1997-2008, porque algunos programas de inversión fueron temporales, como el caso de los PIDIREGAS, o en el caso de la deuda porque los datos llegan hasta 2016. Los datos que ocupan un lugar relevante en este artículo corresponden a números de proyectos anuales, inversión PIDIREGAS 
y sin PIDIREGAS, gastos de inversión física total, las exportaciones petroleras respecto al total, la producción, el precio promedio por barril, los balances energéticos y financieros propios de PEMEX, la deuda y las tasas impositivas de la OCDE y México. En la segunda fase se revisó la literatura existente respecto al tema energético en México, incluyendo un apartado histórico y de antecedentes de la industria petrolera, en el cual se incluyó el análisis de textos, revistas y periódicos especializados sobre el tema de la reforma energética. Para aclarar la relación entre exportaciones petroleras y el precio promedio de la mezcla mexicana, se construyó un índice de correlación.

\section{RESULTADOS}

\section{Antecedentes de la industria petrolera en México}

En México, la historia comercial del petróleo se remonta a 1863 cuando un cura de nombre Manuel Gil y Sáenz descubrió un yacimiento superficial que llamó Mina de Petróleo de San Fernando, cerca de Tepetitlán, Tabasco. Sin embargo, la primera compañía que extrajo petróleo de pozos perforados y produjo destilados fue la Compañía Explotadora de Petróleo del Golfo de México, organizada en 1868 por Adolfo Autrey, un médico norteamericano de origen irlandés, que fracasó. Los individuos o pequeñas corporaciones que pretendieron hacer del petróleo un negocio redituable a lo largo de las últimas décadas del siglo XIX fracasaron debido a los pocos recursos financieros que podían invertir, a las complicaciones geográficas, la ausencia de trabajadores capacitados y de mercados amplios y seguros. La contribución más importante que hicieron fue la localización de lo que serían las zonas más importantes de yacimientos, base de los auges petroleros del siglo XX: la denominada Faja de Oro, en el norte de Veracruz, y los campos de Reforma en Tabasco.

Con la llegada de Porfirio Díaz al poder en 1876, se crearon las condiciones para permitir la entrada de capitales del exterior. Como señala Collado (1987): «entre 1876 y 1910 se privatizó el subsuelo petrolero y, al amparo de esa legislación, surgió en México, con capital extranjero, la industria de los hidrocarburos - porque - se creía entonces en México que el capital nacional era insuficiente para poner en marcha el desarrollo industrial y además la mayor parte de los empresarios se mostraban temerosos de invertir en ramas desconocidas para ellos» (p. 54).

Empezaron así a llegar grandes empresas americanas e inglesas que «dotadas de un know how que estas compañías habían construido poco a poco, aprovecharon la inexperiencia de países poco desarrollados industrialmente, pero dotados de abundantes recursos de hidrocarburos» (Rousseau, 2017, p. 49). Así fue como atraídos por la potencialidad de las reservas petroleras en México, el petrolero norteamericano Edward L. Doheny y el constructor británico Weetman D. Pearson, organizaron las primeras grandes empresas integradas verticalmente, la Mexican Petroleum Company y la Compañía Mexicana de Petróleo El Águila, con las que dominaron la industria petrolera durante el primer cuarto del siglo XX. La llegada de estos empresarios norteamericanos se explica según Meyer (1981) por tres razones:

En primer lugar, porque la demanda del combustible era ya importante, sobre todo en los países industriales; en segundo término, porque México constituía la prolongación natural de los campos petroleros tejanos, y, por último, porque al finalizar el siglo XIX, los Estados Unidos eran ya definitivamente un país exportador de capitales y México un vecino bien dispuesto a recibirlos. (p. 1) 
Los descubrimientos de grandes yacimientos en la región norte de Veracruz dieron pie al primer auge de la industria petrolera de 1911 a 1921, incrementando la producción de 3.6 millones de barriles anuales en 1910 a 12.5 millones en 1911 -periodo en el que las empresas petroleras privadas empezaron a exportar crudo a EE.UU. y Gran Bretaña- y de ahí en adelante la producción se incrementaría cada año hasta 1921, cuando alcanzó el nivel máximo y México llegó a ocupar el segundo lugar como productor mundial. Posteriormente, debido al agotamiento de los depósitos más ricos en la Faja de Oro, a partir de 1921 la producción petrolera en México fue en franco descenso. El panorama se complicó con la caída de los precios internacionales, las iniciativas fiscales y los cambios normativos que promovieron los gobiernos revolucionarios. Entre ellos destaca la nueva Constitución de 1917 que sentó las bases para la expropiación petrolera de 1938 (Álvarez, 2005).

En 1919, la Royal Dutch-Shell compró El Águila a Weetman D. Pearson. Y, por su parte, Doheny vendió la Pan-American Eastern a la compañía norteamericana Standard Oil Company en 1925. Así terminaba la era de las grandes empresas individuales al frente de la industria petrolera en México. La llegada de empresas multinacionales dentro del escenario petrolero mexicano se dio básicamente por razones estratégicas. Estas grandes corporaciones veían a las compañías individuales como un peligro que podría provocar una disminución en sus ventas o arrebatarles los mercados vecinos. Los problemas que enfrentaron las compañías petroleras fueron la caída de la producción, más por su incapacidad tecnológica que financiera, para aprovechar otros yacimientos a mayor profundidad. En 1924, México aportaba casi el 14 \% de la producción mundial y para 1930 esa proporción se redujo solo al $3 \%$. En gran medida, este cambio se debió al surgimiento de otras zonas de explotación en el mundo, con costos de producción más bajos que en México, que provocaron un incremento de la oferta mundial, la caída de los precios del crudo y la reducción de los volúmenes de producción del petróleo mexicano. Finalmente, entre 1933 y 1937 la producción se incrementó, causando cierto optimismo en cuanto al futuro de la industria petrolera en México. Sin embargo, a partir de entonces, no serían los grupos internacionales los encargados de desarrollar dicha industria.

Desde los años veinte el Gobierno procuró regular la producción de petróleo y lograr un mayor control de la industria petrolera por medio de una institución pública denominada Control de Administración del Petróleo Nacional (CAPN), encargada de la producción de crudo y refinación en terrenos federales. En 1933, el proyecto de una empresa nacional cobró forma con la creación de la Compañía Petróleos de México, S. A. (PETROMEX), una empresa de capital mixto que sustituyó al CAPN, pero la falta de inversión y la baja producción obstaculizaron su consolidación. Ante la necesidad de un mejor control de la industria petrolera, el Gobierno creó en 1937 una organización que dependía directamente del ejecutivo, la Administración General del Petróleo Nacional (AGPN), a la que traspasó las propiedades de PETROMEX con el objetivo de regular el mercado interno de petróleo y refinados y asegurar el abastecimiento interno. Fue así como el presidente Cárdenas decretó, el 18 de marzo de 1938, la expropiación de la industria petrolera y el día siguiente la AGPN se hizo cargo provisionalmente de los bienes expropiados de las compañías petroleras. Según Brown (2005):

La nacionalización de la industria petrolera mexicana no fue un proceso dramático que se llevó a cabo durante un solo día, el 18 de marzo de 1938, sino que fue un proceso mucho más gradual y largo, que empezó a gestarse desde que los petroleros extranjeros entraron al país y que continuó con rapidez después de 1920 en la época de consolidación de la revolución. (p.58) 
Además, como señala Rousseau (2017), este proceso de nacionalización de las compañías privadas internacionales no tenía como

Único objetivo controlar el tesoro petrolero. Fueron antes que nada actos destinados a afirmar la soberanía y el desarrollo económico y social del país. Se trataba de otorgar al Estado un papel central en la economía, en participar en la industria. (p. 119)

La industria recién nacionalizada necesitaba de una gran reorganización que el Gobierno intentó realizar creando dos instituciones en junio de 1938: Petróleos Mexicanos (PEMEX), que se encargaría de la exploración, producción y refinación, y la Distribuidora de Petróleos Mexicanos, encomendada del mercadeo de petróleo y derivados dentro y fuera del país, tanto de Pemex como de la AGPN. Finalmente, surgieron una serie de problemas internos y por decisión gubernamental PEMEX obtuvo el control total de la industria a partir de agosto de 1940. Los primeros años después de la nacionalización fueron complicados, como deja ver la siguiente entrevista que realizó Olvera (1989) a Heriberto Martínez en Poza Rica, Veracruz el 12 de mayo de 1983:

Después de la nacionalización las compañías extranjeras impusieron un boicot a la industria. No había refacciones ni se podían conseguir barrenas para seguir perforando. Por ahí el Gobierno consiguió comprar en el mercado negro diamantes de perforación. Yo, como soldador, tenía que ponerlos en las barrenas que fuimos a recoger a los tiraderos de chatarra. Ensayé varias formas de colocarlos y luego anduve preguntándole a los perforadores que tan buenas les habían salido mis barrenas. Así como yo inventé una forma de reutilizar las barrenas, los compañeros de pailería y del torno hicieron maravillas para fabricar las piezas que se descomponían en las máquinas y a veces para reponer partes completas de motores o de mecanismos que se utilizan en la industria. De no ser por esta voluntad nuestra de usar nuestros conocimientos para sacar adelante la industria, yo no sé qué hubiera pasado. Los ingenieros se fueron todos. Los nuevos ingenieros jóvenes que mandó el Gobierno no sabían absolutamente nada. La verdad es que los primeros tres o cuatro años en la industria se hizo lo que opinaban los trabajadores calificados. (p. 182)

Entre 1938 y 1946 se conformó el marco legal que dio a PEMEX el carácter de empresa pública. Algunos problemas que retrasaron su consolidación y expansión fueron el aumento de la demanda interna que terminó superando los niveles de producción, la política de precios bajos que el Gobierno impuso a la empresa que dañó severamente sus ingresos y, por ende, su disponibilidad para invertir. Durante los dos periodos administrativos de J. Bermúdez (1946-52, 1952-58), PEMEX dio los primeros pasos hacia la integración vertical, es decir, para llegar a controlar todas las fases del proceso productivo desde la extracción hasta la comercialización. El marco jurídico había definido a PEMEX como una empresa pública, cuyos objetivos eran conservar y aprovechar los recursos petroleros, atender el mercado interno abasteciéndolo oportunamente y exportando los excedentes de la producción, contribuir al gasto público mediante el pago de impuestos, mejorar el nivel cultural de los trabajadores petroleros y crear beneficios colectivos en las zonas de explotación.

Entre 1946 y 1958 PEMEX se convirtió en una empresa consolidada y en proceso de expansión con toda la infraestructura necesaria para surtir las necesidades del mercado interno. Sin embargo, un problema grave que enfrentó la empresa fue la falta de recursos para su expansión, en parte por la política de precios, al tener que comercializar sus productos con precios bajos, y también por las altas cargas fiscales a las cuales estaba sometida, que limitaban la posibilidad de reinvertir sus ingresos en actividades de exploración, extracción, comercialización y refinación (Álvarez, 2006). Entre 1959 y 
1973 la expansión de PEMEX sufrió una desaceleración importante que culminó en una crisis productiva. Todos los errores cometidos en las actividades de exploración, producción y refinación, tales como las preferencias a las perforaciones de desarrollo en detrimento de las perforaciones exploratorias que postergaron el descubrimiento de nuevos depósitos, más las complicaciones económicas por la incapacidad de la empresa para financiar con recursos propios su costosa expansión, derivaron en una crisis de abastecimiento del mercado interno que estalló en la década de 1960, obligando a PEMEX a la importación de crudo. En 1966 PEMEX dejó de exportar crudo por primera vez en su historia. Tuvieron que pasar cerca de tres décadas, desde la expropiación, para implementar un programa de investigación científico y de ingeniería en el sector petrolero mexicano. Fue así como en 1965 se creó el Instituto Mexicano del Petróleo (IMP) «...para enfrentar en la década de 1960 la búsqueda de un margen de autonomía en el manejo de los recursos naturales y tecnología, intensificar la exploración petrolera, perforar a mayores profundidades y satisfacer el incremento de la demanda interna» (Guajardo, 2004, p. 4).

Las perforaciones de desarrollo tienen la finalidad de explotar, extraer y drenar las reservas de un yacimiento. El objetivo principal al perforar un pozo en la modalidad de desarrollo es aumentar la producción del campo, razón por la cual, se perforan dentro del área probada. Mientras que las perforaciones exploratorias tienen como objetivo continuar con la exploración del subsuelo y evaluar las reservas potenciales de hidrocarburos, con el fin de descubrir nuevos yacimientos. Se perfora como investigación en zonas donde no se había encontrado antes petróleo ni gas.

El escenario petrolero internacional se transformaría a principios de la década de los setenta:

todavía las Majors ocupaban una posición dominante: controlaban $80 \%$ de las exportaciones mundiales y $90 \%$ de la producción del Medio Oriente. Sin embargo, los acontecimientos del último trimestre de 1973 cuestionaron de manera radical las reglas del juego en el ámbito internacional. Por un lado, la producción de crudo incremental de Estados Unidos conoció su pico histórico en 1970. (Rousseau, 2017, p. 241)

Si hasta ese momento, en palabras de Rousseau (2017), Pemex «había vivido alejada del mundo, replegada sobre ella misma, desconociendo los códigos en vigor en el mercado internacional» ( $p$. 319), los acontecimientos de esta década modificarían sus planes abriéndose nuevamente al mercado petrolero mundial.

PEMEX comenzó a recobrar el camino hacia la autosuficiencia productiva en 1974, con la reanudación de las exportaciones cuando la empresa echó a andar un programa de perforaciones en los campos de Reforma y en la sonda de Campeche, donde se descubrió el complejo Cantarell. Esto se dio en el contexto favorable de las dos crisis mundiales del petróleo, que para México significaron grandes ganancias por los mayores ingresos de divisas, una en 1973 y la otra en 1979, caracterizadas por los grandes incrementos en los precios del crudo. En 1982 la producción nacional anual llegó a los 1002 millones de barriles, con la cual México se colocaba en la cuarta posición entre los productores mundiales de petróleo. El gran auge petrolero de estos años llevó al Gobierno a replantear el papel de PEMEX dentro de la economía nacional. A partir de la administración del director general Jorge Díaz Serrano (1976-1981), PEMEX hizo de la exportación masiva el eje fundamental de su expansión. Esta nueva política de exportaciones generaría las divisas para sacar al país de la crisis económica y sería el motor del desarrollo económico nacional (Álvarez, 2006). Sin embargo, a partir de los años 
ochenta se presentó una caída generalizada de los precios del crudo que colapsaron a principios de 1986, esto debido a la sobreoferta petrolera mundial, afectando a los países productores de petróleo, entre ellos México. Los precios se mantuvieron bajos por algunos años, lo cual impidió a México desarrollar plenamente sus capacidades como exportador. A partir de 1983, la administración de PEMEX aplicó planes más restrictivos y cautelosos con el fin de lograr ahorros y hacer más eficiente su desempeño. Así mismo, los ajustes posteriores a la crisis de la deuda externa mexicana provocaron la disminución de las actividades de la empresa petrolera.

Estos cambios contemplaron principalmente la modernización del aparato productivo, el incremento del ahorro interno y una mayor apertura hacia el exterior. Con base en este plan general, la industria petrolera experimentó una reorientación que consistió básicamente en la reducción de los programas de inversión y el incremento de la productividad, la rentabilidad y la eficiencia (Meyer \& Morales, 1990, p. 223, citado en Álvarez, 2006, p. 142).

La inestabilidad del mercado petrolero internacional y los efectos de la recesión en la economía mexicana marcaron el curso de la industria petrolera durante la primera mitad de la década de 1990. A partir de 1996 la producción anual de crudo se fue incrementando hasta alcanzar, en 2004, la cifra de 3 millones 382 mil barriles diarios de petróleo crudo, destacándose en este rubro los campos del complejo Cantarell. Los niveles de inversión requeridos fueron garantizados con un esquema de financiamiento que buscaba atraer el capital privado, sin tener que modificar la Constitución.

\section{Los PIDIREGAS}

Ante la necesidad de las empresas públicas de llevar a cabo proyectos de inversión, en el contexto de la crisis económica mexicana de diciembre de 1994 y tomando en cuenta la dificultad de PEMEX para financiar sus inversiones con recursos propios, se diseñó en el sector energético un esquema de financiamiento proveniente del sector privado conocido como PIDIREGAS (Proyectos de Inversión Diferidos en el Gasto, también llamados Proyectos de Inversión de Largo Plazo).

Con objeto de contar con la infraestructura necesaria para asegurar un abasto oportuno y suficiente de los bienes y servicios que produce el Estado de manera exclusiva, el H(onorable) Congreso de la Unión reformó, en diciembre de 1995, la Ley de Presupuesto, Contabilidad y Gasto Público Federal y la Ley General de Deuda Publica en sus artículos 30 y 18, respectivamente. Estas reformas dieron lugar a los Proyectos de infraestructura productiva de largo plazo, también conocidos como Pidiregas. (Secretaria de Hacienda y Crédito Publico [SHCP], 2016, p. 1)

Los PIDIREGAS se crearon para atraer inversión privada con financiamiento de largo plazo y de esta manera fortalecer la infraestructura productiva en el sector energético mexicano, específicamente en PEMEX. Para llevar a cabo un proyecto PIDIREGAS se procedía de la siguiente manera:

1. Se convocaba a una licitación pública internacional y las empresas ganadoras de las licitaciones se encargaban de la construcción de los proyectos de infraestructura con recursos propios, sin ningún impacto sobre las finanzas públicas.

2. Cuando las obras estaban terminadas y en condiciones de generar ingresos, se entregaban a las empresas del sector público, en este caso PEMEX. 
3. Cuando los proyectos entraban en operación (podía pasar mucho tiempo entre la asignación de la licitación y la entrega de la obra), se iniciaba el pago de obligaciones a través de recursos presupuestales generados por cada uno de los mismos proyectos.

«Solo aquellos proyectos que en el análisis de prefactibilidad que realizan las entidades, tengan una rentabilidad demostrada, y que correspondan a actividades prioritarias o estratégicas en los términos que señala la constitución, podrán calificar» (SHCP, 2016, p. 1). Se pueden distinguir dos tipos de esquemas dentro de los PIDIREGAS: la inversión directa, que por la naturaleza de los contratos obliga a la empresa pública (PEMEX) de manera directa y firme a adquirir los activos productivos construidos por empresas privadas nacionales o extranjeras. El otro se denomina inversión condicionada, en este caso los activos son de propiedad privada y solo se da la adquisición si se presenta alguna eventualidad contemplada en los contratos de suministro de bienes o servicios. Bajo este esquema la empresa pública tiene la opción de decidir si comprar o no el activo, a diferencia de la inversión directa que obliga a la entidad pública a adquirir el activo. En la Tabla 1, se puede observar el número de proyectos asignados en el periodo que se concentra, por más de la mitad en un solo año, el 2002.

Tabla 1. Número de proyectos que iniciaron operaciones cada año

Table 1. Number of projects that started operations per year

\begin{tabular}{ccccccccccccccc}
\hline \multicolumn{10}{c}{ Número de proctos que iniciaron operaciones cada año } \\
\hline Años & 1997 & 1998 & 1999 & 2000 & 2001 & 2002 & 2003 & 2004 & 2005 & 2006 & 2007 & 2008 & TOTAL \\
\hline PEMEX & 4 & 6 & 0 & 0 & 2 & 25 & 0 & 0 & 4 & 1 & 4 & 1 & 47 \\
\hline Directa & 3 & 6 & 0 & 0 & 2 & 25 & 0 & 0 & 1 & 1 & 4 & 1 & 43 \\
\hline Condicionada & 1 & - & - & - & - & - & - & - & 3 & - & - & - & 4 \\
\hline
\end{tabular}

Fuente: elaborado por el Centro de Estudios de las Finanzas Públicas de la Cámara de Diputados, con información de los Presupuestos de Egresos de 2001 a 2007 y Proyecto de PEF 2008, extraído de «PIDIREGAS 2007-2008», (Centro de Estudios de las Finanzas Públicas, 2007, p. 18).

Cabe mencionar que el sistema fiscal mexicano refleja una enorme dependencia de los ingresos fiscales con respecto a los hidrocarburos. Los recursos que le quedan a PEMEX después del pago de impuestos y derechos son insuficientes para lograr sus objetivos de extracción de petróleo, por lo que la empresa recurrió a los PIDIREGAS para financiar sus proyectos de inversión. Este esquema de realización de inversiones en el sector energético con recursos privados resultó ser una fuente muy importante de financiamiento para la industria petrolera por la vía del endeudamiento a largo plazo. Al principio, en 1997, el 14 \% de las inversiones de PEMEX se financiaban mediante los PIDIREGAS, sin embargo, la deuda de PEMEX contraída a través de esta fuente de financiamiento fue aumentando rápidamente al grado que, en 2007, los PIDIREGAS financiaban el $90 \%$ de las inversiones de PEMEX. Una situación bastante complicada para la paraestatal, como se demuestra en la Figura 1. 


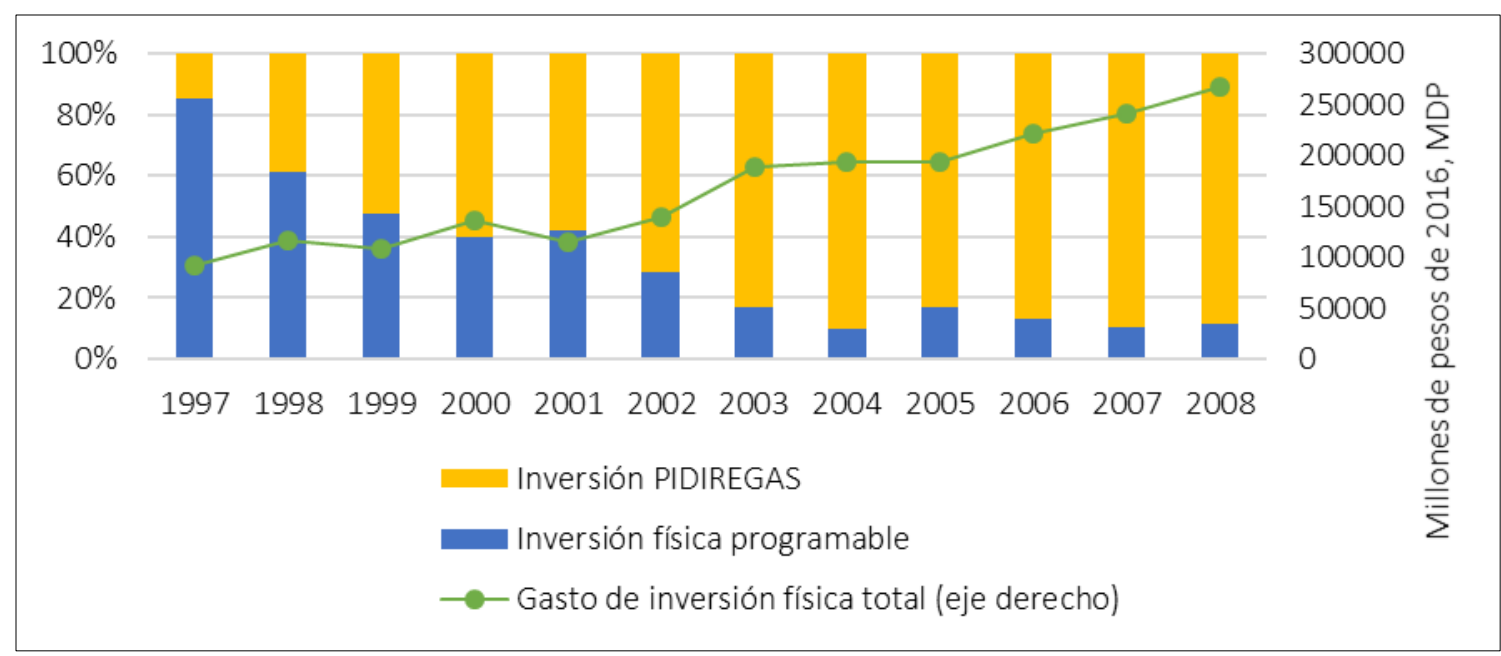

Figura 1. Endeudamiento de Pemex mediante los PIDIREGAS

Figure 1. PEMEX debt though PIDIREGAS

Fuente: elaboración propia con datos derivados de (PEMEX, 2020).

Los PIDIREGAS beneficiaron en el corto plazo al sector energético mexicano, en específico a la industria petrolera, "como generadores de ingresos y creadores de infraestructura de gran envergadura» (Centro de Estudio de las Finanzas Públicas [CEFP], 2007, p. 22), sin embargo, también hubo aspectos críticos, ya que «el esquema de endeudamiento es muy oneroso para PEMEX y poco claro» (Rousseau, 2010, p. 322). Una de las desventajas del endeudamiento, es que el Gobierno deberá desembolsar 567 mil 718 millones de pesos hasta el 2031, por el pago de los intereses de las adquisiciones al sector privado, a lo que Reyes Tépach (2008) señala:

El cumplimiento de las obligaciones contraídas en materia de tasas de interés representa el costo de oportunidad que tiene que pagar el Gobierno Federal por reducir el gasto público en infraestructura productiva para el sector petrolero y canalización a otros rubros del gasto (p. 30).

Ante tal situación, el endeudamiento de PEMEX con el sector privado para llevar a cabo sus proyectos de inversión no tiene por qué ser la única vía para cumplir con sus funciones productivas, existen otras alternativas y no necesariamente implican la apertura al capital extranjero.

\section{Petróleo y sector servicios}

Durante los últimos 38 años las exportaciones petroleras cada vez han perdido más importancia dentro de las exportaciones totales. Si a principios de los años ochenta habían llegado a representar cerca del $80 \%$ del total, a partir de 1991 empezaron a perder peso significativamente reduciéndose a menos del 20 \%, la disminución siguió sucesivamente hasta llegar al 5 \% en 2016 (Figura 2). 


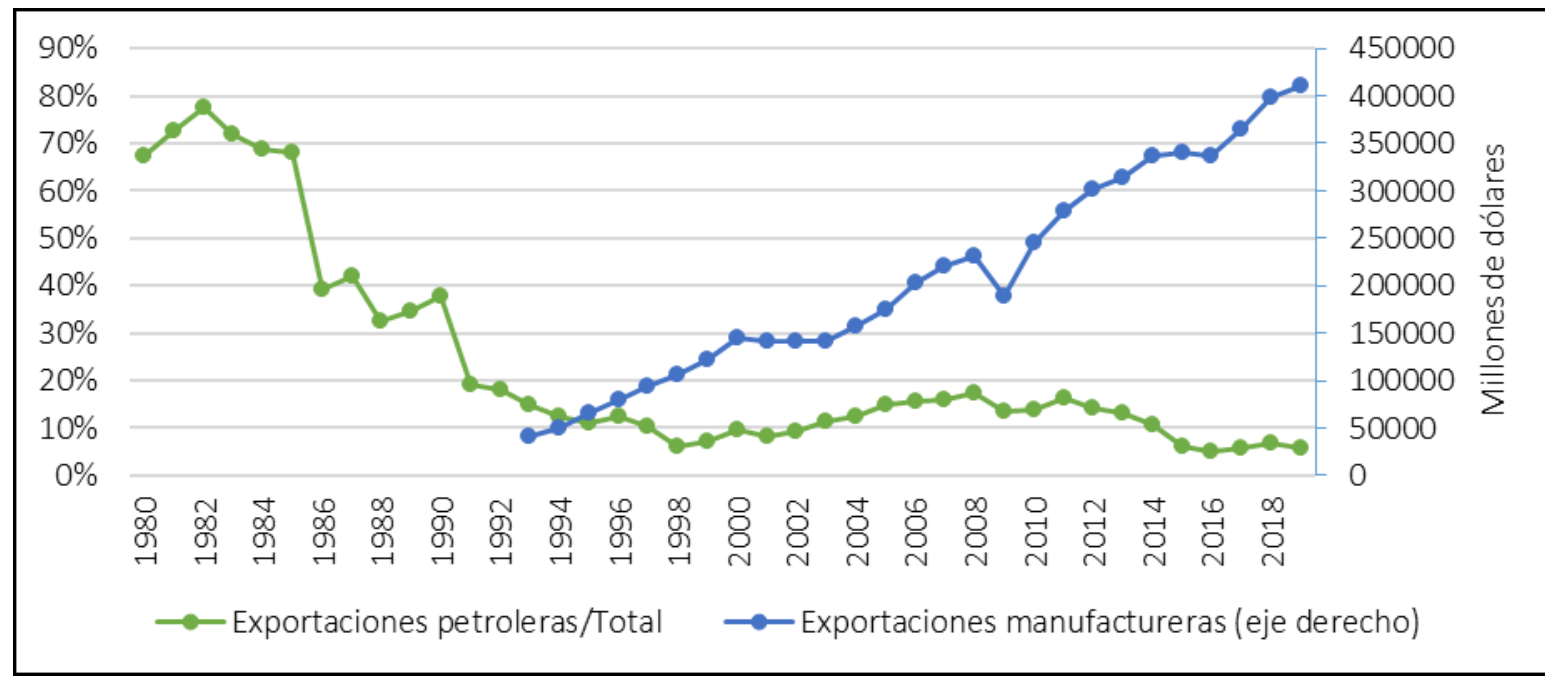

Figura 2. Total de exportaciones petroleras en relación con total exportaciones manufactureras Figure 2. Oil exports compared to total exports and manufacturing exports Fuente: elaboración propia con datos derivados de (INEGI, 2020).

La caída de las exportaciones petroleras sobre el total tiene tres causas principales: la primera es el consistente incremento de las exportaciones manufactureras (que aumenta el denominador), como se muestra en la figura 2 en el eje de la derecha; la segunda es la reducción del precio del petróleo (que repercutió mucho en los últimos años) en los mercados internacionales; y, la tercera, la reducción de la producción interna de petróleo en la última década (Figura 3).

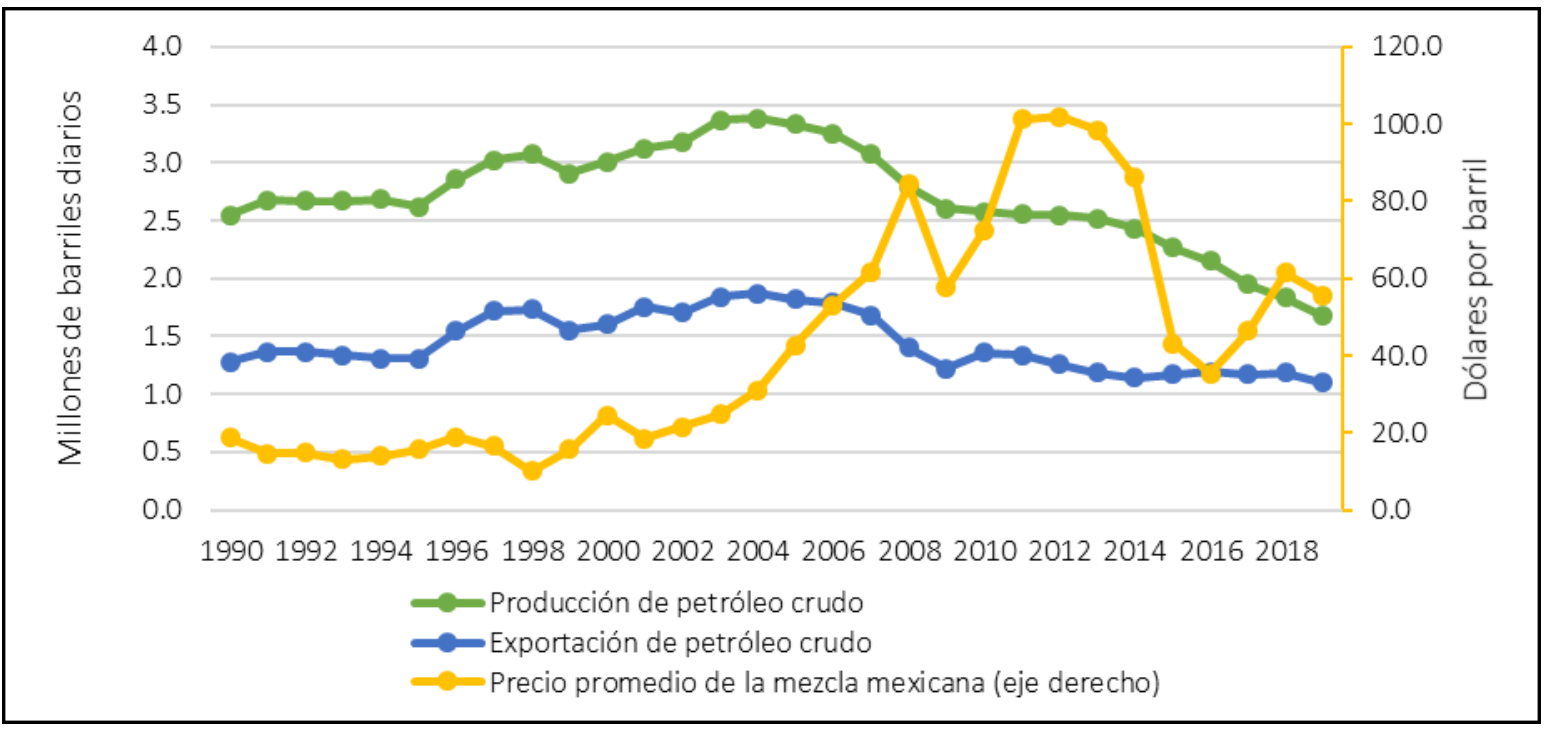

Figura 3. Producción, exportación de petróleo crudo y precio promedio

Figure 3. Production and exports of crude oil and average price Fuente: elaboración propia con datos derivados de (PEMEX, 2020; INEGI, 2020).

Factores externos tales como la incertidumbre en el mercado mundial del petróleo y las fluctuaciones de los precios internacionales han golpeado fuertemente a PEMEX. Las decisiones de los países miembros de la Organización de Países Exportadores de Petróleo (OPEP), a la cual México no 
pertenece, y a partir de los años noventa los acuerdos entre todos los productores (OPEP y no OPEP), han determinado los precios mundiales del petróleo, afectando a la industria petrolera mexicana en el valor de sus ingresos totales, ya que existe una muy alta correlación entre el precio promedio de la mezcla mexicana y el valor de las exportaciones totales de PEMEX. Con datos del INEGI, se ha calculado el coeficiente de correlación entre estas dos variables, que resulta ser de 0.97 en el periodo 1980-2018, muy cercano a 1, el valor que indica la máxima correlación.

De 1980 a 2004 el precio promedio del crudo no superó los 35 dólares por barril. Desde fínales de la década de los ochenta y en toda la década de los noventa el precio osciló entre 10 y 20 dólares. A partir del 2001 los precios empezaron a mejorar significativamente alcanzando su nivel máximo en 2012, 102 dólares por barril (Figura 3, eje derecho), lo que significó un gran incremento de la entrada de divisas al país. En los últimos años se ha planteado la importancia de mejorar las estrategias para minimizar los riesgos asociados a las grandes fluctuaciones de los precios mundiales, ya que en 2011 y 2012 el precio promedio de la mezcla mexicana de petróleo superaba los 100 dólares por barril y en 2016 se precipitó hasta 36 dólares.

Uno de los principales objetivos que tiene PEMEX como empresa paraestatal es satisfacer la demanda interna y exportar los excedentes hacia las diversas regiones. La producción y exportación de petróleo crudo en México a lo largo de los últimos 28 años ha tenido oscilaciones bastante pronunciadas. Por ejemplo, la producción alcanzó un tope en 2004 y desde entonces se ha reducido en un 45 \% (Figura 3). La producción petrolera de las últimas dos décadas ha estado marcada, por un lado, por el crecimiento sostenido que tuvo a partir de la segunda mitad de la década de los noventa hasta alcanzar a su punto más alto en 2004. Sucesivamente inició el declive de la producción de petróleo crudo, que desde 2005 ha venido disminuyendo rápidamente. Más preocupante aun es que esta tendencia no se ha logrado revertir. En gran medida esto se debe a que uno de los campos petroleros supergigantes dejó de ser importante en términos de producción. Se trata del complejo Cantarell descubierto en 1976, que alcanzó su pico de producción en 2004, cuando llegó a representar el 63 \% de la producción total. Sin embargo, en 2009 su producción se había reducido hasta el 26 \% de la producción total. Ante la crisis productiva de PEMEX y el agotamiento de yacimientos importantes como Cantarell, Lajous (2010) señala:

Las consecuencias para el país de la declinación previsible no deben subestimarse. Obligan a dar mayor importancia al uso eficiente de energía y a revisar la conveniencia de mantener niveles elevados de exportación, ante una reducción en la vida media de las reservas probadas que las ha llevado a niveles preocupantes. Colocan en un primer plano la prioridad de avanzar en la administración de yacimientos, mejorar prácticas productivas, apoyarse en sistemas de recuperación mejorada y acelerar el cambio tecnológico en las actividades de exploración y desarrollo. (p. 408)

\section{Las causas de la crisis petrolera y la reforma energética}

El comercio de hidrocarburos en el exterior ha sido sumamente importante para la economía mexicana y PEMEX una fuente considerable de recursos fiscales para el Gobierno federal. México es un país que exporta petróleo crudo e importa derivados del crudo (gasolina, diésel, etc.) para el funcionamiento de las empresas automotrices, de las industrias manufactureras y para usos domésticos, y entre 1990-2014 la balanza de productos petroleros había sido superavitaria (Figura 4). 


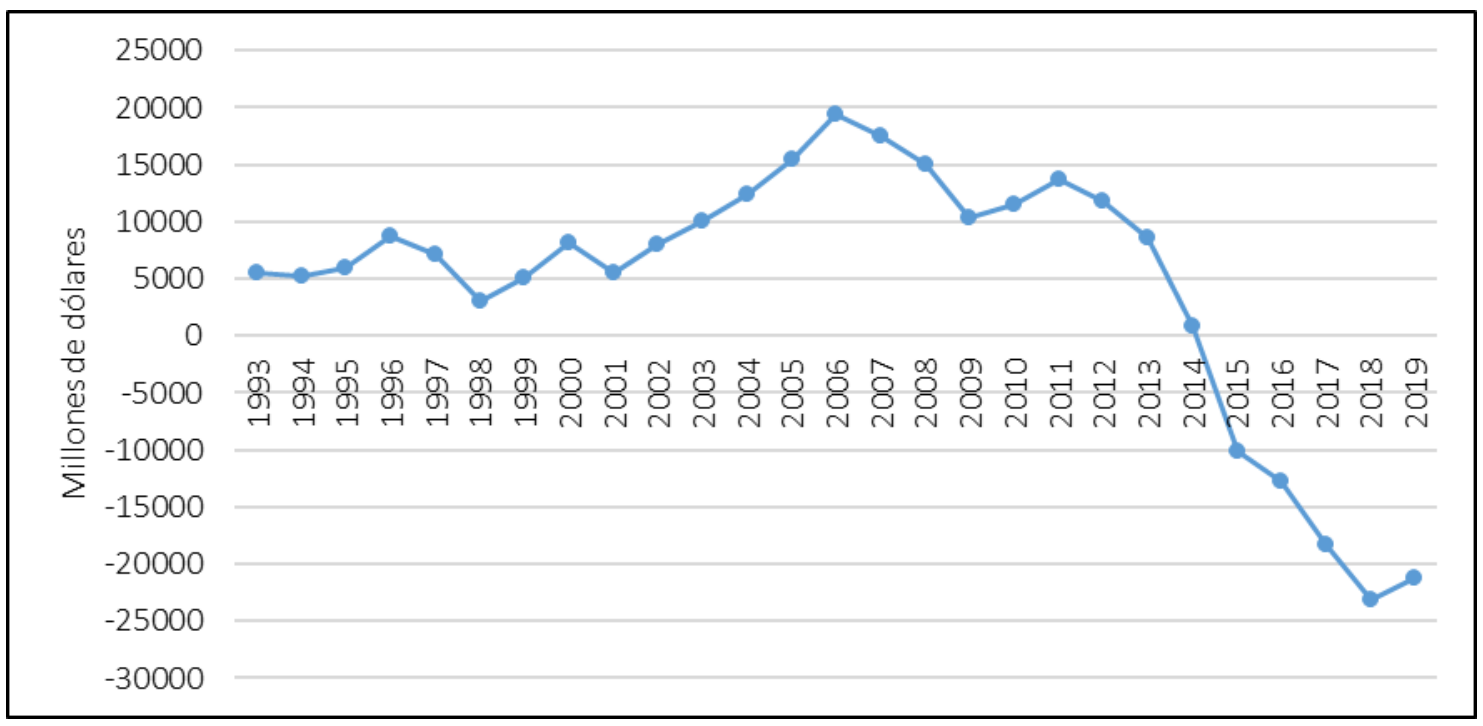

Figura 4. Balanza de productos petroleros (X-M)

Figure 4. Balance of oil products (X-M)

Fuente: elaboración propia con datos derivados de (INEGI, 2020).

Sin embargo, desde el 2015 la balanza de productos petroleros presenta un déficit como consecuencia de la baja producción de la empresa estatal, que ha repercutido en menores exportaciones y de la incapacidad de desarrollar una industria de refinación para producir los derivados que ahora se importan (gasolina, diésel etc.).

Vidal (2017) afirma:

En el año 2014 el saldo del comercio exterior de la industria de petróleo fue particularmente reducido. En años previos, con precios elevados en los mercados internacionales de hidrocarburos y una extracción creciente de petróleo crudo en México, las exportaciones superaban ampliamente a las importaciones en esta actividad industrial. En 2014 el saldo positivo según información reciente de Banco de México fue de apenas 880 millones de dólares, una cifra muy menor comparada con la obtenida en 2012, del orden de 11 mil 817 millones de dólares. (párr. 1)

En un contexto de precios del petróleo a la baja, la balanza petrolera de México fue afectada por el diferencial de precios entre exportaciones e importaciones (X-M), mayores importaciones de derivados del petróleo y un estancamiento del volumen exportado.

Siempre, según Vidal (2017):

Las importaciones de gasolinas son un aspecto del funcionamiento de la industria petrolera que hace parte de la reforma energética, como mantener la venta de gasolina como un medio para recaudar impuestos. Actualmente el precio de la gasolina en México es superior al precio medio en Estados Unidos. Por ello en la frontera se aplica un programa de subsidios con cargo al fisco para intentar evitar la compra de gasolinas al otro lado del rio Bravo. (párr. 9)

Uno de los grandes problemas de la empresa petrolera mexicana PEMEX, quizás el más importante, ha sido su bajo nivel de inversión en exploración, producción y refinación. En la Figura 5a (inversión 
física total que incluye inversión PIDIREGAS) se puede apreciar que durante la década de los noventa y principio de este siglo, la inversión física se mantuvo muy baja en valores absolutos (a precios constantes de 2018). Aun cuando la producción de petróleo crudo llegó a su pico en 2004 en un entorno de los precios del crudo al alza, PEMEX no realizó mayores inversiones productivas. A partir de 2006, la inversión ha aumentado relativamente, pero esta reactivación no ha sido suficiente para evitar la crisis productiva de PEMEX de los últimos años, porque la escasa inversión en años anteriores no permitió la exploración de nuevos yacimientos, y los que se encontraban en operación se habían acabado como el complejo Cantarell. Otro indicador que permite aclarar la situación de la inversión productiva en PEMEX es la relación entre inversión física y los ingresos totales de la empresa. En la Figura 5a (eje de la derecha) se puede observar la situación de la inversión física como porcentaje del ingreso corriente total, tomando en cuenta el esquema de financiamiento PIDIREGAS de 1997 a 2008. Esta figura muestra que, con el inicio de los PIDIREGAS, en 1997, la inversión en relación con el ingreso total de PEMEX creció de manera importante, casi se triplicó en solo dos años, pasando del $10 \%$ en 1996 a 28 \% en 1998. Pero en general, la inversión total desde la década de los noventa hasta el 2018 resultó ser muy baja, entre el $10 \%$ y el $22 \%$ del ingreso total.

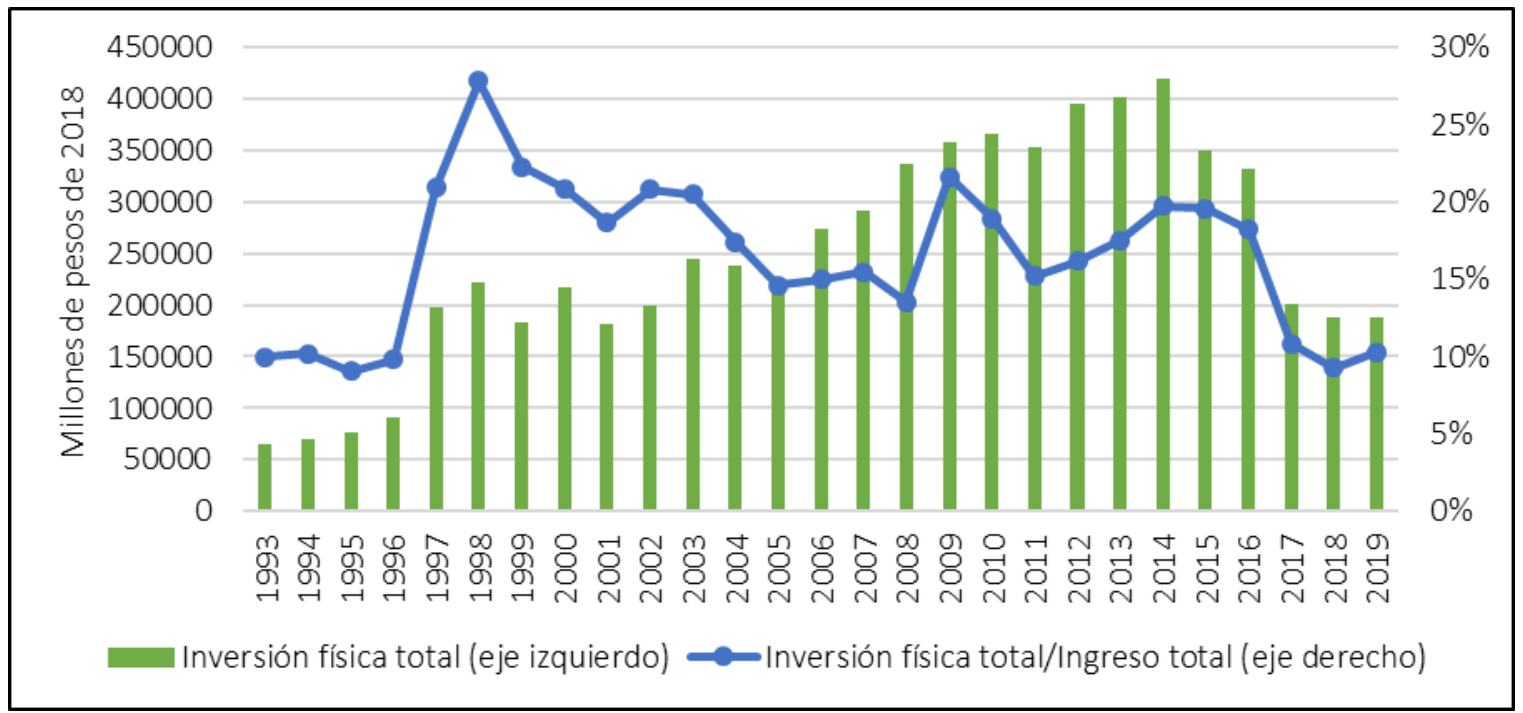

Figura 5a. Inversión física total de PEMEX

Figure 5a. Total physical investment by PEMEX

Fuente: elaboración propia con datos derivados de (PEMEX, 2020).

Sin embargo, la mayor parte de la inversión física que se llevó a cabo en PEMEX durante el periodo 1997-2008 no se hizo con recursos públicos, sino bajo el esquema PIDIREGAS, con el cual se llegó a financiar hasta el 90 \% de las inversiones de la empresa paraestatal. La Figura 5b muestra precisamente esta situación: la inversión física sin tomar en cuenta la inversión PIDIREGAS ha estado realmente en niveles muy bajos. Esto significa que, durante esta década, PEMEX estuvo financiando sus inversiones a través de deudas contratadas, en su mayoría, con empresas privadas extranjeras, casi sin utilizar recursos propios. En la Figura $5 b$ (eje de la derecha) se ve el estado de la inversión en relación con los ingresos totales sin tomar en cuenta los PIDIREGAS de 1997 a 2008. Esta figura pone en evidencia los niveles extremadamente bajos de inversión pública efectuados en el sector energético, que disminuyeron constantemente en el periodo de los PIDIREGAS, llegando a representar entre 2005 y 2008 solo el 1 \% de los ingresos totales de PEMEX. 


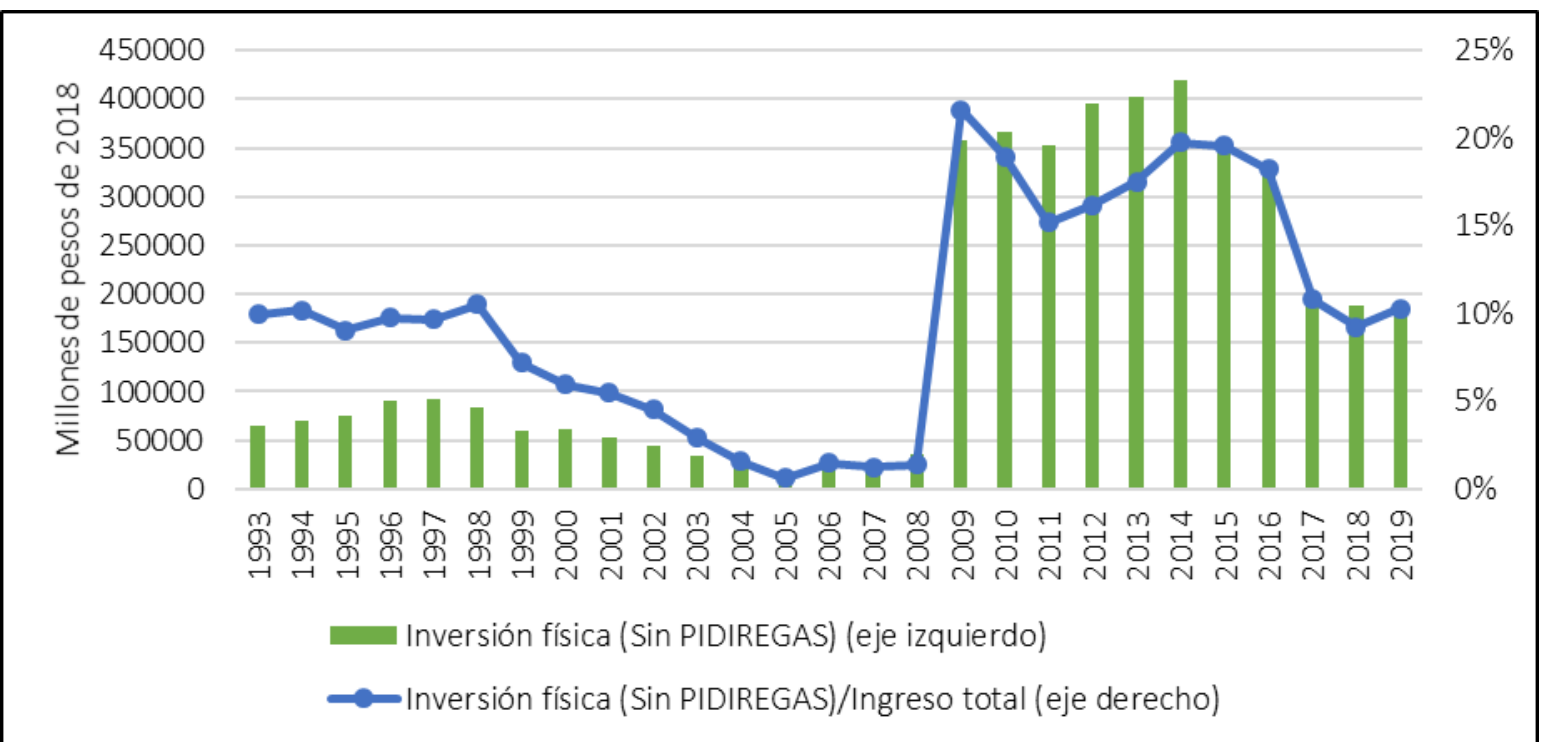

Figura 5b. Inversión física de PEMEX (sin PIDIREGAS)

Figure 5b. Total physical investment by PEMEX (without PIDIREGAS)

Fuente: elaboración propia con datos derivados de (PEMEX, 2020).

En la Figura 6 es posible apreciar la inversión, el pago de los impuestos, derechos y aprovechamientos que realiza PEMEX y el gasto de operación medido como porcentaje de los ingresos totales. Resalta la excesiva carga fiscal a la que ha estado sujeta la empresa petrolera estatal, ya que la mayor parte de los ingresos de PEMEX se destinan al pago de impuestos, derechos y aprovechamientos. Siendo la principal empresa que por muchos años ha aportado a las finanzas públicas. La inversión productiva ha resultado ser muy baja en la década de los noventa y a principios de este siglo, y solo en los últimos años ha crecido modestamente. Aunque también en los últimos años los otros gastos han tenido un incremento notable, representando el 35 \% del total en 2019. Estos gastos hacen referencia a otros gastos de operación, donativos, costo financiero y los saldos netos de las operaciones ajenas por cuenta de terceros, así como diversos gastos supervenientes como indemnizaciones y laudos laborales, que por su naturaleza no pueden ser previstos. 


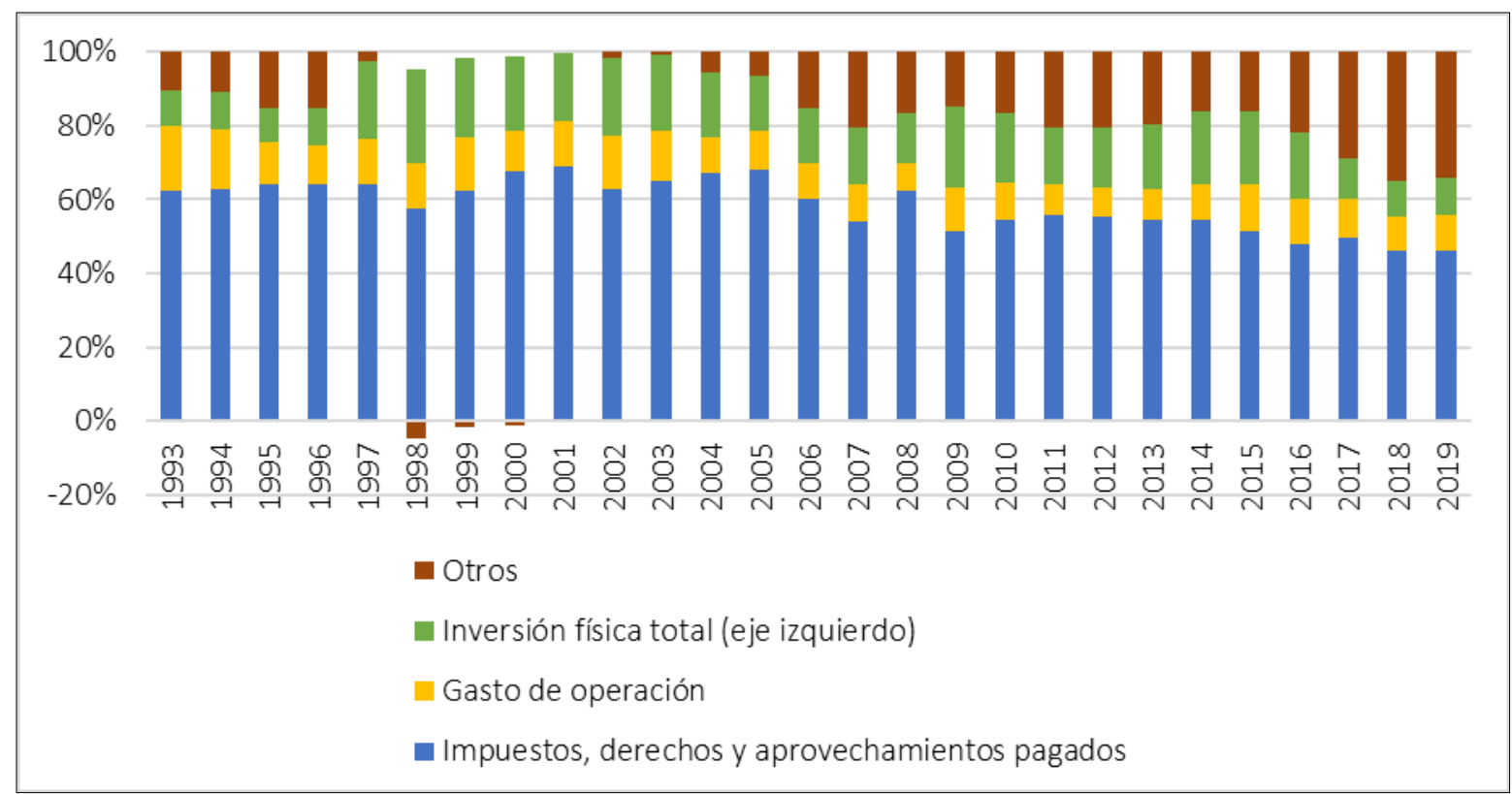

Figura 6. Balance financiero de PEMEX

Figure 6. Financial balance of PEMEX

Fuente: elaboración propia con datos de (PEMEX, 2020).

El gasto de operación que incluye gastos en servicios personales y generales, salarios y el pago de la nómina de pensiones ha mostrado una ligera disminución en los últimos años y en 2019 este rubro representó el 9.5 \% del total de los ingresos. Por tanto, este no es el principal problema de PEMEX; más bien son las excesivas obligaciones fiscales impuestas a la empresa, esto por la estructura del sistema fiscal mexicano que depende mucho de los ingresos petroleros, como bien señala Tello (2015):

La enorme riqueza petrolera de los últimos 30 años, que ha proporcionado considerables recursos al Gobierno (el precio promedio de la mezcla mexicana de exportación pasó de 16 dólares por barril en 1995 a más de 100 dólares en 2012), lo ha llevado a continuamente posponer una reforma tributaria. (p. 13)

Por tanto, si se reduce la carga fiscal sobre la empresa petrolera esta tendría más recursos para financiar sus inversiones en exploración, extracción y refinación. Otro problema que atañe a PEMEX es su deuda, que se ha incrementado a lo largo de los 12 años, como se muestra en la Tabla 2.

Tabla 2. Deuda total e impuestos, derechos y aprovechamientos pagados Table 2. Total debt and paid taxes, fees, and benefits

\begin{tabular}{cccccccccccccc}
\hline Años & 2004 & 2005 & 2006 & 2007 & 2008 & 2009 & 2010 & 2011 & 2012 & 2013 & 2014 & 2015 & 2016 \\
\hline $\begin{array}{c}\text { Impuestos, derechos } \\
\begin{array}{c}\text { y aprovechamientos } \\
\text { pagados/ICT }\end{array}\end{array}$ & $67 \%$ & $68 \%$ & $60 \%$ & $54 \%$ & $62 \%$ & $52 \%$ & $54 \%$ & $56 \%$ & $55 \%$ & $54 \%$ & $54 \%$ & $52 \%$ & $48 \%$ \\
\hline Deuda total/ICT & $63 \%$ & $59 \%$ & $51 \%$ & $42 \%$ & $35 \%$ & $54 \%$ & $47 \%$ & $44 \%$ & $41 \%$ & $45 \%$ & $63 \%$ & $95 \%$ & $121 \%$ \\
\hline
\end{tabular}

Fuente: elaboración propia con datos derivados de (PEMEX, 2020). 
En 2008 la deuda equivalía al 35 \% de los ingresos corrientes totales (ICT), y en 2016 superaba el $121 \%$, y según Solís (2019): "se contrajo principalmente para financiar gastos de operación y de inversión necesarios para sus operaciones debido a su carga fiscal - pago de derechos de extracción de hidrocarburos-» (párr. 5). Esta situación ha propiciado la crítica por parte del Gobierno y la propuesta de una reforma energética para promover la llegada de empresas extranjeras que inviertan en el sector energético nacional. Sin embargo, la debilidad financiera de la empresa paraestatal, como hemos visto, tiene otras causas.

En 1938 el general Lázaro Cárdenas decretó la nacionalización petrolera con base en el artículo 27 de la Constitución Política de los Estados Unidos Mexicanos, donde prácticamente la nación pasó a ser dueña de todos los minerales (sólidos, líquidos y gaseosos), incluyendo el petróleo. En el caso del petróleo, la infraestructura de las compañías petroleras extranjeras que operaban en territorio mexicano fue expropiada y pasó al Estado, previa indemnización. A partir de entonces, PEMEX asumió un papel protagónico en el sector de hidrocarburos en distintas actividades como la exploración, producción, refinación y comercialización del petróleo crudo.

En 1940 se aprobó la Ley Reglamentaria del artículo 27 Constitucional en materia de petróleo, promulgada por el presidente Lázaro Cárdenas, la cual mencionaba que:

El petróleo será explorado y explotado por la Nación mediante trabajos realizados en forma directa y podrán celebrarse contratos con los particulares, a fin de que estos lleven a cabo, por cuenta del Gobierno Federal, los trabajos de exploración y explotación, ya sea mediante compensaciones en efectivo o equivalentes a un porcentaje de los productos que se obtengan. (Diario Oficial de la Federación, 1940, p. 3)

Se aclara que, los contratos solo se podían concluir con nacionales o con sociedades constituidas íntegramente por mexicanos, en ningún caso con sociedades anónimas que emitan acciones al portador (art. $9^{\circ}$ de la Ley Reglamentaria del art. $27^{\circ}$ Constitucional en Materia de Petróleo, 1940).

La ley daba la posibilidad a PEMEX de aliarse con empresas mexicanas para poderse beneficiar de sus avances tecnológicos cuando lo considerara necesario, pero prohibía las concesiones. Sin embargo, el gobierno de Cárdenas hizo hincapié en la nacionalización del petróleo como una afirmación de soberanía, tema muy popular en México, que había sido defraudado en el siglo anterior de más de la mitad de su territorio por parte de los Estados Unidos de América.

Una enmienda constitucional a principios de los años sesenta le quitó a PEMEX esta posibilidad y solo con la reforma energética (RE) del 2013 se reintrodujo en el artículo 27 y en los artículos transitorios. México llegó a principio de los setenta, en la víspera de los shocks petroleros, con una producción que todavía no había recuperado la de 1921. Solo la «maldición del Cantarell» (Wood y Martin, 2018 p. 24) permitió al país beneficiarse de los enormes aumentos del precio del petróleo en la década del setenta, dejando de lado el debate sobre el sector energético y sobre la necesaria reforma fiscal para reducir sustancialmente la enorme carga tributaria que grababa sobre Pemex. Además, según Wood y Martin (2018) el descubrimiento del Cantarell ha permitido al Gobierno obtener fácilmente recursos sin tener que reformar el sistema tributario y energético llegando a afirmar la paradoja que contribuyó a retardar el desarrollo del país. 
En 1992 se crearon PEMEX Petroquímica, PEMEX Gas y Petroquímica Básica, PEMEX Refinación y PEMEX Exploración y Producción como organismos subsidiarios de PEMEX, en el intento de mejorar la administración de la paraestatal, profundizando, generalizando e institucionalizando el cálculo económico en todas las actividades y sujetando las decisiones a criterios de rentabilidad financiera (Tec Beltrán, 2018), y así reducir los altos niveles de corrupción en PEMEX. En ese periodo inició el declive natural del Cantarell y la revolución de la lutita Barnett, (las lutitas son rocas de granos finos ricos en material orgánico y pobres de oxígenos que, a diferencia de la arcilla y el lodo, están laminadas en estratificaciones muy finas que se pueden separar con la estimulación hidráulica, por eso se consideran depósitos de hidrocarburos no convencionales) que introdujo en gran escala el fracking (hidrofracturación), un método no convencional de extracción de gas y petróleo que requiere de avances tecnológicos que PEMEX aún hoy no domina. Los gobiernos panistas de Fox y Calderón lograron posponer la RE a través de los PIDIREGAS que, como hemos visto, no duraron más de una década; al mismo tiempo, el intento de sustituir el Cantarell con Chicontepec también fracasó, pues la producción en este último campo nunca logró niveles considerables. En esta situación, faltaba solo que se crearan condiciones políticas más favorables para que el PRI y el PAN se unieran y realizaran la reforma constitucional necesaria para reestructurar el sector energético, y estas se concretaron después de la aplastante victoria de Peña Nieto en las elecciones de 2012.

El 12 de agosto de 2013 el mismo presidente Peña entregó su iniciativa de reforma de los artículos 27 y 28 de la Constitución Política de los Estados Unidos Mexicanos al Senado de la República, esta reforma constitucional abarcó también los artículos 25 y 28; sin embargo, las modificaciones más importantes están en el artículo 27. "Las iniciativas se acompañaron de diagnósticos de diferente profundidad, en los cuales se referenciaron algunos indicadores relacionados con la producción, el consumo y el comercio exterior de petróleo, hidrocarburos y electricidad» (Del Río Mongues et al., 2017, p. 14). El argumento que sostenía el poder ejecutivo ante la necesidad de introducir una RE era que se habían destinado cuantiosas inversiones en exploración y extracción de petróleo y que aún no se veían reflejadas por una mayor producción, asumiendo sobre todo que el petróleo de fácil acceso se estaba agotando también en México. La otra argumentación que sostenía la iniciativa de la Reforma Energética se organiza en seis ejes estratégicos: 1) fortalecer la rectoría del Estado sobre la industria petrolera; 2) mayor inversión y empleos con el impulso de los recursos energéticos; 3) desarrollo incluyente para las distintas regiones; 4) seguridad energética; 5) transparencia sobre la administración del patrimonio energético; y, 6) sustentabilidad y protección al medio ambiente (Alejo, 2014, p. 28). La RE fue promulgada el 20 de diciembre de 2013, y a continuación (Tabla 3) reportamos el artículo 27 modificado donde se puede comparar la anterior formulación con la que queda plasmada en la reforma. 
Tabla 3. Artículo 27 de la Constitución Política Mexicana que se reformó con la Reforma Energética de Enrique Peña Nieto en 2013

Table 3. Article 27 of the Mexican Political Constitution, which was amended by Enrique Peña Nieto's Energy Reform in 2013

\begin{tabular}{|c|c|}
\hline Antes de la reforma & Después de la Reforma Energética (2013) \\
\hline $\begin{array}{l}\text { Art. } 27^{\circ} \text { Tratándose del petróleo y de los carburos } \\
\text { de hidrógeno sólidos, líquidos o gaseosos o de } \\
\text { minerales radioactivos, no se otorgarán } \\
\text { concesiones ni contratos, ni subsistirán los que en } \\
\text { su caso se hayan otorgado y la Nación llevará a cabo } \\
\text { la explotación de esos productos, en los términos } \\
\text { que señale la Ley Reglamentaria respectiva. } \\
\text { Corresponde exclusivamente a la Nación generar, } \\
\text { conducir, transformar, distribuir y abastecer } \\
\text { energía eléctrica que tenga por objeto la prestación } \\
\text { de servicio público. En esta materia no se otorgarán } \\
\text { concesiones a los particulares y la Nación } \\
\text { aprovechará los bienes y recursos naturales que se } \\
\text { requieran para dichos fines (así formulado el } 6 \text { de } \\
\text { febrero de 1975). }\end{array}$ & $\begin{array}{l}\text { Art. } 27^{\circ} \text { Tratándose del petróleo y de los } \\
\text { hidrocarburos sólidos, líquidos o gaseosos, en el } \\
\text { subsuelo, la propiedad de la Nación es inalienable e } \\
\text { imprescriptible y no se otorgarán concesiones. Con } \\
\text { el propósito de obtener ingresos para el Estado que } \\
\text { contribuyan al desarrollo de largo plazo de la } \\
\text { Nación, esta llevará a cabo las actividades de } \\
\text { exploración y extracción del petróleo y demás } \\
\text { hidrocarburos mediante asignaciones a empresas } \\
\text { productivas del Estado o a través de contratos con } \\
\text { estas o con particulares, en los términos de la Ley } \\
\text { Reglamentaria. Para cumplir con el objeto de dichas } \\
\text { asignaciones o contratos las empresas productivas } \\
\text { del Estado podrán contratar con particulares. En } \\
\text { cualquier caso, los hidrocarburos en el subsuelo son } \\
\text { propiedad de la Nación y así deberá afirmarse en las } \\
\text { asignaciones o contratos. }\end{array}$ \\
\hline
\end{tabular}

Fuente: H. Congreso de la Unión, Cámara de Diputados LXIV Legislatura: Diario oficial de la Federación.

Con la aprobación de la RE se replanteó para PEMEX asumir nuevas responsabilidades dentro de la administración pública, así como ocupar nuevas funciones (exploración y producción, cogeneración de servicios, producción y distribución de fertilizantes y etileno, perforación y servicios, transformación industrial, y la parte logística junto con terceros) al realizar sus actividades de exploración y producción de petróleo, ya fuera de manera independiente o en asociación o consorcio con la iniciativa privada. Según Jaúregui (2018) «Entre otras cosas, suprimió el monopolio estatal en la exploración y explotación de hidrocarburos y buscó desarrollar la apertura del sector de energía eléctrica a la participación de particulares en ciertas actividades» (párr. 1). Nos parece importante señalar que los cambios principales de la RE no fueron introducidos en la Constitución, sino en las disposiciones transitorias (nos referimos específicamente a los tipos de contratos que Pemex puede suscribir con empresas del sector privado, que vienen mencionados en las disposiciones, mientras en el artículo 27 solo se hace referencia a esa posibilidad.). Según García Sánchez (2018) eso representa una debilidad de la RE, que se somete así a los cambios de ciclo político por no haber confiado en la capacidad de modificar los artículos constitucionales correspondientes, lo cual la hubiese blindado de las acciones de nuevos gobiernos contrarios a la misma RE.

En agosto de 2014 fueron aprobadas las leyes secundarias en el Congreso para regular los diferentes mecanismos y tipos de contratos que el Gobierno podrá utilizar con el objetivo de obtener ingresos que promuevan al desarrollo de la nación y para impulsar un uso más productivo y sostenible de los recursos naturales. "Al final del proceso, se involucraron 21 leyes, de las cuales se expidieron 9 y se reformaron 12» (Del Río Mongues et al., 2017, p.46).

Según Mujeres en Energía (2018): 
Las modificaciones a los artículos $25^{\circ}, 27^{\circ}$ y $28^{\circ}$ de la Constitución Política aprobadas en 2013 establecen que la exploración y extracción de hidrocarburos se mantiene como área estratégica del Estado quien, a través de contratos, asigna a Pemex y a terceros el desarrollo de dichas actividades bajo criterios de sustentabilidad. El capital privado puede participar en toda la cadena de valor, de manera directa y mediante alianzas con Pemex. Potencialmente cualquier empresa que cumpla con los requisitos establecidos por los reguladores y otras autoridades puede realizar actividades desde la exploración y producción de hidrocarburos hasta su expendio final, asumiendo riesgos e invirtiendo. (párr. 12)

Otro analista sintetiza así la reforma constitucional:

La reforma propuesta para el artículo 27 consiste en dos elementos en materia de hidrocarburos: primero, eliminar la prohibición de celebrar contratos de explotación de yacimientos de hidrocarburos entre el Estado y particulares y, segundo, remitir a la Ley Reglamentaria del artículo 27 en esta materia, la determinación de la forma en que la nación llevará a cabo las explotaciones de los hidrocarburos. (Alejo, 2014, p. 29)

De lo anterior se aclara que, Pemex puede estipular los siguientes contratos: 1) de efectivo en cambio de servicios, 2) con coparticipación en las ganancias, 3) con coparticipación en la producción, 4) de licencia (en este caso el hidrocarburo se transfiere después de haber sido extraído del suelo). Como observa García Sánchez (2018, p. 45), «de las 6900 palabras que conforman la reforma energética mexicana, 6000 se encuentran en los artículos transitorios» y no en la Constitución, lo cual somete la misma reforma a los vaivenes del ciclo político, además de asignar un margen discrecional para la interpretación de los contratos a la Corte Suprema.

El cambio de dueño de los minerales o combustibles como el petróleo, puede darse a través de alianzas entre la compañía nacional petrolera y operadores privados, o simplemente a través de contratos y licencias a empresas privadas. En realidad, como se ha anticipado, el corazón de la reforma no está en los cambios constitucionales, sino en los artículos transitorios donde se mencionan los cuatro tipos de contratos que PEMEX puede suscribir con empresas privadas, también extranjeras, es decir, licencias, producción compartida, participación en ganancias, servicio. La reforma también consistió en fortalecer los dos órganos reguladores en el sector energético, la Comisión Nacional Hidrocarburos $(\mathrm{CNH})$ como «la reguladora de la fase aguas arriba creada durante la reforma de 2008, con la capacidad de ofrecer concesiones y contratos con participantes privados del mercado para la exploración y producción de hidrocarburos en México» (Wood y Martin, 2018, p. 32) y la Comisión Reguladora de Energía (CRE)

en su función de otorgar permisos de generación eléctrica, permisos en las actividades de la industria de hidrocarburos (transporte, almacenamiento, distribución, compresión, licuefacción, descompresión, regasificación, comercialización y venta de hidrocarburos) productos al público, y permisos para la gestión de sistemas integrados. Estas entidades administrativas se consideran órganos descentralizados (órganos desconcentrados) del Gobierno federal que están reconocidos por el artículo 28 de la Constitución como órganos reguladores coordinados del sector energético y tienen autonomía en sus funciones del Ministerio de Energía. (García Sánchez, 2018, p. 54)

En el consejo de administración de PEMEX se pasó de 15 a 10 miembros, removiendo a los representantes sindicales acusados de haber tolerado y estimulado, en las más altas esferas, las prácticas de corrupción dentro de la paraestatal. En el intento de reducir el déficit de la empresa, 
30000 trabajadores fueron despedidos entre 2013 y 2016, y fue reformado el régimen de jubilación privilegiado, del cual se beneficiaban los trabajadores de PEMEX, acercándolo al de los funcionarios públicos.

Es importante recordar que PEMEX ha venido en un proceso de declive de la producción desde hace más de una década, y todavía en el año 2003 la empresa paraestatal ocupaba la tercera posición en el ranking de las empresas internacionales por su producción de petróleo crudo, aunque empezó a tener un patrimonio negativo y con utilidades negativas a partir de 2005. Desde la aprobación de la RE en 2013 y de las leyes secundarias en 2014, PEMEX comenzó un proceso de planeación en todas sus empresas para la instrumentación de esta. Por lo que ha realizado diferentes cambios en la estructura logística para que la empresa se apegue a las nuevas reglas del sector hidrocarburos, como la apertura del sector al libre mercado, la participación de la iniciativa privada en actividades de exploración y producción, esto con el fin de que pueda operar de manera eficiente y sea rentable para el Estado y competitiva en el sector hidrocarburos. Sin embargo, el sector petrolero en México se enfrenta a retos muy complejos que podrían desembocar en una aguda crisis petrolera. En primer lugar, PEMEX ha tenido baja producción en los últimos años, mientras tanto los pozos cada vez son más viejos, su explotación requiere de una tecnología más sofisticada, de la cual la paraestatal no dispone. Se pudo comprobar que existen yacimientos denominados no convencionales, en contraposición a los que tradicionalmente se han venido explotando (convencionales).

El petróleo del futuro provendrá siempre más de los llamados yacimientos no convencionales y de los que se encuentran en cuencas y aguas profundas, con elevados costos de explotación. En lugar de abrir una reflexión sobre la oportunidad de introducir técnicas sofisticadas como el fracking, con elevados costos en términos de la afectación del medioambiente, el Gobierno de Peña Nieto decidió abrir las puertas a los inversionistas extranjeros en nuestro país, conjeturando que el desarrollo del sector energético requiere de muchos recursos financieros y de tecnología avanzada que PEMEX no tiene. El propósito es aumentar la exploración y producción de hidrocarburos, crear competencia en los procesos de refinación, petroquímica y transporte de hidrocarburos, fortalecer a la Comisión Nacional de Hidrocarburos, convertir a PEMEX en el motor de una cadena de proveedores nacionales y en la producción nacional de fertilizantes.

Después de la aprobación de la RE a finales del 2013 y con el reordenamiento y reestructuración de sus leyes secundarias, en el sector energético empezó una transformación como sugería el Gobierno mexicano. Mientras tanto, después de que terminara la promulgación de la ley energética, la Secretaría de Energía (SENER) presentó las Ilamadas «rondas» donde las empresas privadas y las empresas productivas del Estado podrían participar o trabajar en conjunto. A partir de entonces se abrieron 4 rondas de licitaciones, con una ronda inicial (ronda 0) en la cual, según el sexto artículo transitorio de la reforma constitucional, se le otorga a PEMEX la posibilidad de elegir los campos donde desea trabajar, antes de asignar las licitaciones. En la ronda 0:

El organismo (PEMEX) debería someter a consideración de la Secretaría del ramo en materia de Energía (Secretaría de Energía) la adjudicación de las áreas en exploración y los campos que estén en producción, que esté en capacidad de operar, a través de asignaciones. Para lo anterior, deberá acreditar que cuenta con las capacidades técnicas, financieras y de ejecución necesarias para explorar y extraer los hidrocarburos de forma eficiente y competitiva. La solicitud se deberá presentar dentro 
de los noventa días naturales siguientes a la entrada en vigor del presente Decreto (21 de marzo de 2014) (DOF 20, 12, 2013, citado en Ramones Fernández, 2014, p. 1).

Sucesivamente han tenido lugar tres rondas y la Comisión Nacional de Hidrocarburos (CNH) se encargó de adjudicar los contratos en cuatro licitaciones de la ronda 1, en cuatro de la ronda 2 y en la tercera ronda se preveían licitar 3. La primera licitación de la ronda 1, en julio de 2015, no dio buenos resultados, hubo poca participación por los criterios demasiado restrictivos que se establecían, y solo dos de los catorce bloques que se ofertaban fueron asignados. La segunda licitación fue más exitosa y de los cinco bloques ofrecidos, tres fueron asignados. La tercera se caracterizó por la participación de empresas mexicanas y la asignación de 18 de los 25 bloques de las subastas. Solo en la cuarta y última licitación de la ronda 1 se llegó a ofertar campos en aguas profundas. En la ronda 2 hubo una mayor participación y 19 de los 29 bloques fueron asignados. Entre la ronda 1 y 2 se firmaron más de 90 contratos y en el periodo de vigencia de ellos se estima que la inversión pueda alcanzar los 150.000 millones de dólares.

El nuevo gobierno respeta los contratos que se le otorgaron al sector privado durante las licitaciones de las dos rondas, pero canceló dos de las tres que se programaban en la ronda 3. Por tanto, PEMEX sigue produciendo petróleo junto con la iniciativa privada en el Gobierno de López Obrador. «Hoy la CNH administra 111 contratos y 415 asignaciones de PEMEX. Por una parte, administra, y por la otra, regula las actividades petroleras de PEMEX y de 76 empresas de 20 países» (Mares, 2019, parr. 29).

\section{DISCUSIÓN}

Elevar la baja carga fiscal ha sido un gran reto para el país. La recaudación fiscal en México en relación con el producto interno bruto (PIB) para el periodo 1990-2018 ha resultado ser muy baja, manteniéndose entre el 12 y el $16 \%$ del PIB. Solo en 2016 alcanzó el $17 \%$, cuando la carga fiscal de la OCDE en promedio se ubica entre el 32 y el $34 \%$ del PIB (Figura 7).

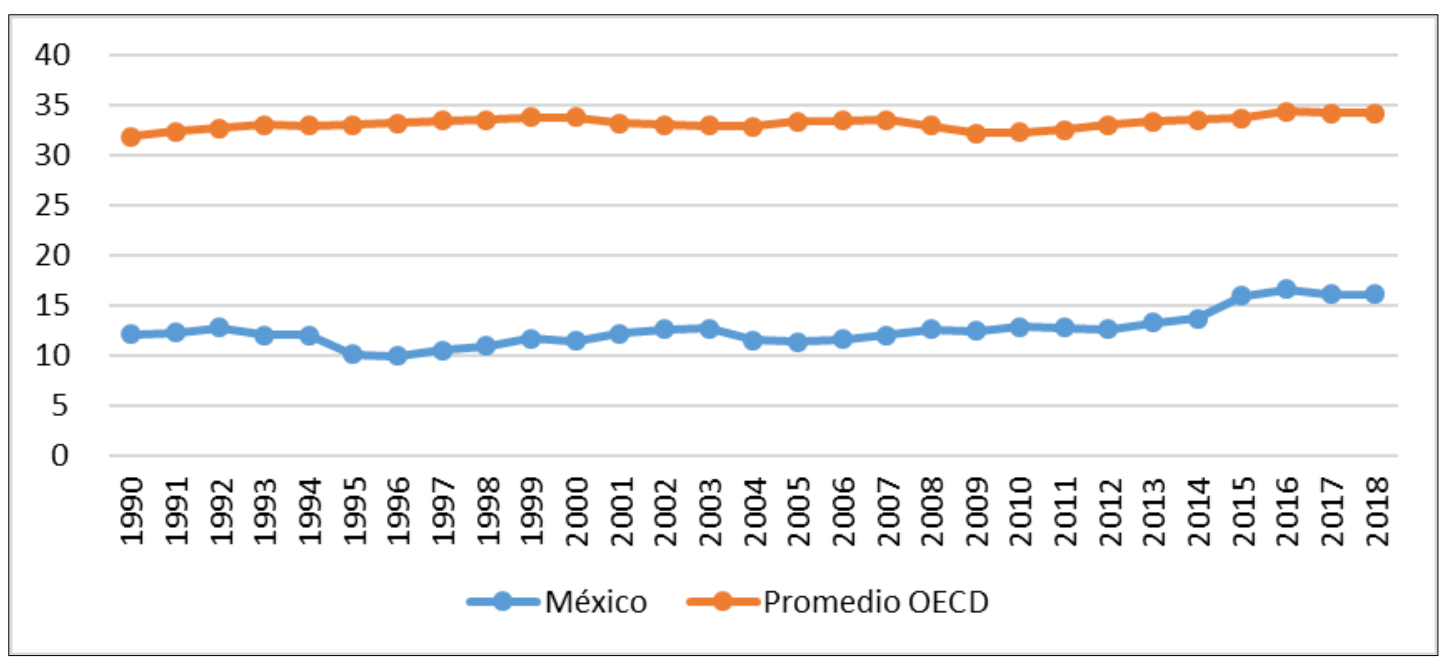

Figura 7. Todos los ingresos fiscales, \% del PIB

Figure 7. All tax revenue, $\%$ of GDP

Fuente: elaboración propia a partir de (OCDE, 2020). 
Esto significa que México tendría que multiplicar por dos la carga fiscal actual para acercarse a los países más desarrollados que conforman la OCDE. Así mismo, a pesar de que en los últimos años la brecha ha empezado a disminuir, aún es muy evidente la total ineficacia del Gobierno mexicano para recaudar impuestos. En la Tabla 4 es posible observar las grandes diferencias entre los impuestos recaudados en la OCDE y en México que explican la baja carga fiscal en nuestro país. En general, los impuestos en México aportan muy poco con relación al PIB, algunos son casi inexistentes como los impuestos a la propiedad y las contribuciones al seguro social también son mínimas, por la elevada informalidad del mercado laboral mexicano.

Tabla 4. Tasas impositivas OCDE y México

Table 4. Tax rates in OCDE countries and México

\begin{tabular}{ccccc}
\hline Ingresos fiscales (2015) & $\begin{array}{c}\text { Impuestos a } \\
\text { bienes y } \\
\text { servicios }\end{array}$ & $\begin{array}{c}\text { Impuestos a } \\
\text { ingresos y } \\
\text { utilidades }\end{array}$ & $\begin{array}{c}\text { Contribuciones a la } \\
\text { seguridad social }\end{array}$ & $\begin{array}{c}\text { Impuestos a la } \\
\text { propiedad }\end{array}$ \\
\hline OCDE & $10.9 \%$ & $11.5 \%$ & $9.0 \%$ & $1.9 \%$ \\
\hline México & $6.3 \%$ & $6.8 \%$ & $2.2 \%$ & $0.3 \%$ \\
\hline
\end{tabular}

Se propone una reforma fiscal que, utilizando los impuestos directos, a ingresos altos y utilidades, incremente la presión fiscal sobre el sector más rico de la población mexicana. En los últimos años la tasa máxima (que se aplica a los ingresos superiores a los 3 millones de pesos anuales) del impuesto sobre la renta ha sido reducida hasta el $35 \%$, muy por debajo del promedio OCDE (cuando en algunos países como Holanda esta tasa llega a ser de 52 \%). Esto es inaceptable en un país como México con altos niveles de desigualdad (Esquivel Hernández, 2015) y es la demostración de que el problema fiscal es de carácter político, causado por la capacidad de presión del decil más rico de la sociedad mexicana, el mismo que, como se dijo, logró detener la reforma Kaldor hace más de medio siglo. Las circunstancias actuales, con un nuevo gobierno progresista que ha puesto la reducción de la desigualdad al centro de su programa, son favorables para implementar estas medidas. Eso implica también reducir la evasión que se concentra en los altos ingresos, acción que el Gobierno está actualmente tratando de implementar, por ejemplo, la campaña del SAT ha resultado en cobros de cientos de millones de dólares a empresas como Walmart, IBM, América Móvil y el reciente pago de 8790 millones de pesos de Coca-Cola Femsa. Como se observa en la Tabla 4, la recaudación del impuesto al ingreso es casi la mitad que el promedio OCDE, lo cual muestra que hay márgenes importantes de recaudación no explotados que afectarían a un sector muy limitado de la población mexicana, también reduciendo la desigualdad.

Con la misma finalidad se puede utilizar el impuesto patrimonial, que no solo podría aumentar la recaudación y reducir la desigualdad, también representaría un avance hacia una descentralización fiscal más eficiente y ordenada que la actual, tratándose de un impuesto de recaudación local, como ha demostrado la amplia literatura sobre federalismo fiscal (Oates, 1993; Tiebout, 1956). En México, la riqueza es aún más concentrada que el ingreso, el último decil concentra el 34 \% del ingreso según la Enigh, y alrededor de $2 / 3$ de la riqueza. Además, el $0.12 \%$ tiene el $43 \%$ de la riqueza total (Esquivel, 2015). El único impuesto patrimonial existente es el predial, que aporta «el 0.2 por ciento del producto interno bruto (PIB), la cifra más baja en América Latina si se compara con el promedio internacional de 2 por ciento» (Espinosa et al., 2018, p. 376). Se trataría de ampliar la base impositiva, incluyendo la riqueza financiera y otros bienes (carros de lujo, yates, etc.) con un criterio de 
progresividad, como ha propuesto recientemente el economista francés T. Piketty. Los bonos de deuda y las acciones emitidas por empresas serían exentos del impuesto patrimonial, para incentivar el empleo productivo del ahorro privado. En México los estados y municipios no aplican estos impuestos porque pueden contar sobre las transferencias del Gobierno federal, en parte financiadas por la contribución de PEMEX a las arcas públicas. Se trataría de interrumpir este ciclo vicioso, dándole finalmente a los estados un poder recaudatorio propio, que los haría más autónomos y posiblemente más cuidadosos del gasto que ejercen, como señala la teoría del federalismo fiscal. El circulo vicioso actual, financiado en parte por PEMEX, transfiere dinero a los gobiernos estatales sin que existan controles efectivos sobre su gestión, como se ha demostrado en otros trabajos (Sovilla et al., 2018). Transfiriendo a los estados y municipios la recaudación de impuestos al patrimonio se eliminaría la carga fiscal sobre PEMEX, se reduciría la desigualdad y, al mismo tiempo, los contribuyentes locales presionarían a los gobiernos estatales a disminuir el despilfarro y la corrupción que, como se ha comprobado en los últimos años, se ha concentrado en este nivel de la administración. Eso último, porque los gobernadores rendirían cuenta a los contribuyentes locales, y no al gobierno central como sucede ahora. De acuerdo con la revista Forbes México (2013), de los 10 ciudadanos mexicanos más corruptos en 2013, 5 eran gobernadores o exgobernadores: A. Granier Melo (Tabasco), T. Yarrington (Tamaulipas), H. Moreira Valdés (Coahuila), A. Montiel Rojas (Estado de México) y F. Herrera Beltrán (Veracruz). A principios de 2017, 16 exgobernadores tenían juicios pendientes y 8 de ellos estaban en la cárcel.

Una última acción que se recomienda va en el sentido de reducir la economía informal, donde está trabajando más de la mitad de la población económicamente activa. Eso permitiría aumentar sobre todo las contribuciones a la seguridad social, actualmente al $2.2 \%$ del PIB, mientras en la OCDE están en el $9 \%$. También en este caso se ha demostrado la viabilidad de programas de empleo público que sustituyan los programas sociales basados en las transferencias monetarias, que no han tenido efectos en términos de reducción de la pobreza y la informalidad laboral (Sovilla, 2018). Inicialmente se trataría de reforzar programas públicos de creación de empleo como Sembrando Vida, con el cual la actual administración está tratando de reducir la pobreza en las zonas rurales del sureste mexicano, para luego extenderlos a otros sectores también en las zonas urbanas.

Este trabajo plantea la necesidad de entender el problema petrolero mexicano no solo como parte de una nueva política energética, sino como un problema de política pública complejo y que requiere de soluciones integrales de política económica. La reforma energética no será suficiente ni hará más competitivo el sector energético si se deja de lado el problema fiscal. La relación PEMEX-Estado ha sido desigual, porque este, abusando de su soberanía, impuso una sobrecarga tributaria a la empresa pública. Una reforma fiscal que modernice el sistema tributario mexicano, acercándolo al de los países OCDE, además de hacer más competitiva a PEMEX, consolidaría las finanzas públicas que dejarían de depender de las oscilaciones del mercado mundial del petróleo, fortaleciendo así la acción de Gobierno.

Como se ha demostrado, una característica del sistema fiscal mexicano ha sido la gran dependencia de las finanzas públicas de los ingresos petroleros. Si bien es cierto que, a través de sus aportaciones a Hacienda PEMEX ha hecho una apreciable labor social y económica para el país, financiando parte del gasto público mexicano, sus obligaciones hacia el Gobierno han sido excesivas, ya que «el peso del petróleo en las cuentas fiscales de la nación no guarda proporción con el peso de la actividad petrolera en el PIB o en el balance del comercio exterior» (Rousseau, 2010, p. 321). Esto ha creado 
graves problemas a la empresa petrolera, obligándola a reducir la inversión e incrementar su deuda. Según información del INEGI, los ingresos petroleros en el periodo 1986-2014 fueron en promedio el $44 \%$ del total de los ingresos presupuestales del Gobierno federal, llegando a casi el $50 \%$ en 2008, y han disminuido solo en los últimos años (en 2018 solo representaron el $16 \%$ del total de los ingresos del gobierno federal).

La excesiva carga fiscal a la que está sujeta PEMEX es la principal causa de la baja inversión de la empresa petrolera, cuya consecuencia es la crisis productiva actual. La empresa pública pudo destinar mayores recursos a la inversión física en los últimos años, pero esto no ha sido suficiente para frenar el declive de la producción de petróleo. Por otro lado, PEMEX ha dejado de lado la inversión en la refinación, considerando más conveniente importar mayores cantidades de gasolina, gas natural y productos petroquímicos, al punto que el país ha perdido la independencia energética. Esta situación, que dio origen a la RE aprobada en 2013 con profundos cambios en la Constitución, ha implicado la apertura de la industria petrolera mexicana al capital privado, permitiendo la participación de empresas privadas por sí solas o en asociación con PEMEX en actividades antes consideradas exclusivas de PEMEX. De esta manera el Estado mexicano ha perdido el control sobre un recurso natural estratégico para la vida nacional.

En este trabajo se trató de demostrar que la RE más exitosa y conveniente para el país es la que viene acompañada de una reforma fiscal para poder reducir la carga impositiva de PEMEX, sin que disminuyan los ingresos tributarios del Gobierno federal. Para que el Estado mexicano pueda retomar el control de la industria petrolera es necesario acompañar la RE con la implementación de una reforma fiscal que permita aumentar los ingresos no petroleros. Esta reforma serviría para despetrolizar las finanzas públicas, permitiendo reducir sustancialmente la enorme carga fiscal impuesta a PEMEX para que la empresa pública pueda utilizar una gran parte o la totalidad de sus utilidades para financiar sus inversiones no solo para aumentar la producción, sino también en la refinación del petróleo, sin estar obligada a endeudarse, como ha sucedido con los PIDIREGAS. Se evitaría así la cesión al capital privado de la administración de un recurso natural tan estratégico para la nación como el petróleo, y se recuperaría la autonomía energética.

\section{CONCLUSIONES}

Como se ha señalado, en los primeros años PEMEX apoyó el proceso de industrialización del país, y a partir de los años setenta ha cumplido principalmente con dos funciones en la economía mexicana: la de generar divisas y contribuir a financiar el gasto público a través del pago de impuestos. Sin embargo, en las últimas dos décadas PEMEX ha venido en un proceso de declive en su producción; además los precios del petróleo han caído en el mercado internacional. En 2003 PEMEX ocupaba todavía la tercera posición en el ranking de las empresas internacionales por su producción de petróleo crudo, aunque después empezó a acumular un patrimonio negativo y con gestiones deficitarias a partir de 2005.

Sin embargo, el Gobierno de Peña Nieto (2012-2018) en su proyecto transformador implementó un paquete de reformas estructurales y envió una iniciativa de ley para una RE al Congreso para rediseñar las atribuciones de PEMEX junto con la participación de la iniciativa privada en actividades de exploración y producción. La iniciativa fue aprobada el 20 de diciembre de 2013 y cambió 
totalmente las formas de gestionar las reservas energéticas del país. Además, revolucionó a PEMEX, obligándola a competir frente a otras empresas petroleras para tener acceso a las reservas de petróleo.

En resumen, la RE suprimió el monopolio estatal en la exploración y explotación de hidrocarburos y abrió el sector energético al sector privado. El principal propósito de la RE era hacer que PEMEX fuera más competitiva en sus distintos sectores debido a que enfrentaba una caída en su producción. Sin embargo, como se ha señalado a lo largo del trabajo, la principal causa de la caída en la producción ha sido la falta de inversión física en exploración y producción. Esta baja inversión en el sector petrolero se explica en gran medida por la enorme dependencia de las finanzas públicas hacia los ingresos petroleros, que ha implicado una excesiva carga fiscal sobre la empresa pública.

Es posible y recomendable subsanar la deuda contraída por la empresa pública y permitirle realizar los niveles de inversión necesarios, reduciendo sustancialmente sus obligaciones fiscales, a través de una reforma fiscal que modernice la recaudación tributaria en México acercándola a los países OCDE. Además de reforzar a PEMEX y permitirle realizar las inversiones necesarias, la reforma fiscal que se ha propuesto reduce la desigualdad -otro problema atávico del país azteca- y podría aumentar la recaudación fiscal de estados y municipios, fortaleciendo el débil y contradictorio esfuerzo descentralizador que empezó hace más de dos décadas.

\section{CONFLICTOS DE INTERÉS}

Los autores declaran que no presentan conflictos de interés financiero, profesional o personal que pueda influir de forma inapropiada en los resultados obtenidos o las interpretaciones propuestas.

\section{CONTRIBUCIÓN DE AUTORES}

Para el desarrollo de este proyecto todos los autores han realizado una contribución significativa especificada a continuación:

Bruno Sovilla: se ha encargado de la parte teórico-metodológica del trabajo, de la interpretación de la información y organización de la propuesta.

Eusebio Gómez Ramírez: ha revisado las fuentes estadísticas y preparado los indicadores, se ha ocupado más precisamente de la descripción de los PIDIREGAS.

Manuel Sánchez Pérez: ha revisado las fuentes estadísticas y preparado los indicadores, se ha aplicado sobre todo en la parte histórica inicial que reconstruye surgimiento y evolución del mercado petrolero en México. 


\section{REFERENCIAS}

Aboites Aguilar, L.; Unda Gutiérrez, M. (Eds.). (2011). El fracaso de la reforma fiscal de 1961: Artículos publicados y documentos del archivo de Víctor L. Urquidi en torno a la cuestión tributaria en México. Colegio de México. https://doi.org/10.2307/j.ctv512s7v

Aguilera, M.; Alejo, F. J.; Navarrete, J. E.; Torres R. C. (2016). Contenido y alcance de la reforma energética. Economía Unam, v. 13, n. 37, 3-44. URL

Alejo, F. J. (2014). Reforma energética y fiscal en México. Universidad Nacional Autónoma de México. $\underline{U R L}$

Álvarez, J. (2005). Los orígenes de la industria petrolera en México 1900-1925. Petróleos Mexicanos.

Álvarez, J. (2006). Crónica del petróleo en México de 1863 a nuestros días. Petróleos Mexicanos.

Barnés de Castro, F. (2013). Situación y perspectivas del gas natural en México. En S. Chacón, y G. Gil Valdivia (Coord.), La reforma energética en México 2013: pensando el futuro (pp. 51-62). Foro Consultivo Científico y Tecnológico, AC. $\underline{\text { URL }}$

Brown, J. (2005). Los archivos del petróleo y la revolución mexicana. América Latina en la Historia Económica, v. 12, n. 1, 49-60. https://doi.org/10.18232/alhe.v12i1.352

Centro de Estudios de las Finanzas Públicas. (2007). PIDIREGAS: temas relevantes sobre finanzas públicas 2007-2008. URL

Centro de Estudios de las Finanzas Públicas (2008). Puntos Relevantes de la Reforma Energética. URL

Collado, M. (1987). El régimen porfirista y la privatización del subsuelo petrolero. Secuencia, v. 0, n. 8, 053. https://doi.org/10.18234/secuencia.v0i08.179

Decreto por el que se reforman y adicionan diversas disposiciones de la Constitución Política de los Estados Unidos Mexicanos, en Materia de Energía [Honorable Congreso de la Unión]. 20 de diciembre del 2013. DOF: 20/12/2013. URL

Del Río Mongues, J. A.; Rosales Reyes, M.; Ortega Olvera, V.; Maya Hernández, S. O. (2017). Análisis de la reforma energética. Colección Reformas estructurales: avances y desafíos, n. 6 . Senado de la República, Instituto Belisario Domínguez. URL

Esquivel Hernández, G. (2015). Desigualdad extrema en México: concentración del poder económico y político. Iguales-Oxfam.

Espinosa, S.; Martínez, J.; Martell, C. (2018). ¿Por qué algunos municipios en México son mejores recaudadores de impuesto predial que otros? Gestión y Política Pública, v. 27, n. 2, 375-395. $\underline{U R L}$ 
Forbes México. (2013). Los 10 mexicanos más corruptos de 2013. URL

Fry, M. (2018). Shifting volumetric imaginaries of oil potential in Mexico's Chicontepec Basin: Investible asset, reserve replacement, and oilfield services zone. Journal of Latin American Geography, v. 17, n. 3, 73-101. https://doi.org/10.1353/lag.2018.0042

García Sánchez, G. J. (2018). Las letras pequeñas de la reforma energética de México. En Wood, D. (Ed.) La Nueva Reforma Energética de México (40-58). Wilson Center México Institute. URL

Greene, D. L.; Liu, C. (2015). U.S. oil dependence 2014: Is energy independence in sight? Energy Policy, v. 85, 126-137. https://doi.org/10.1016/j.enpol.2015.05.017

Guajardo, G. (2004). El papel del Instituto Mexicano del Petróleo en el cambio tecnológico de PEMEX: la búsqueda de un margen de maniobra en el subdesarrollo, ca. 1965-1990. En Congreso de la Asociación Mexicana de la Historia Económica. $\underline{\text { URL }}$

Hammoudeh, S.; Liu, T.; Chang, C. L.; McAleer, M. (2013). Risk spillovers in oil-related CDS, stock and credit markets. Energy Economics, v. 36, 526-535. https://doi.org/10.1016/j.eneco.2012.10.010

Huang, Y. (2002). Between two coordination failures: automotive industrial policy in China with a comparison to Korea. Review of International Political Economy, v. 9, n. 3, 538-573. https://doi.org/10.1080/09692290210150716

Instituto Nacional de Estadística y Geografía - INEGI. (2020). Banco de información económica. URL

Jaúregui, M. (2018, 18 de marzo). Reforma energética: su implementación al 2018. Forbes México. $\underline{U R L}$

Lajous, A. (2010). Evolución y perspectivas de la producción de petróleo y gas natural. En Castañeda Sabino, A. (Coord.), Los grandes problemas de México. Microeconomía. Vol. X, (407-486). El Colegio de México.

Ley Reglamentaria del Artículo 27 Constitucional en Materia de petróleo. 9 de noviembre 1940. DOF 09-11-1940. URL

Mares, M. A. (2019, 09 de julio). Rondas petroleras, ¿Sí o no? El Economista. URL

Meyer, L. (1981). México y los Estados Unidos en el conflicto petrolero 1917-1942. El Colegio de México.

Mujeres en Energía. (2018). ¿Qué ha ganado México con el nuevo modelo energético? Nexos. URL

Oates, W. E. (1993). Fiscal Decentralization and Economic Development. National Tax Journal, v. 46, n. 2, 237-243. URL 
Olvera, A. J. (1989). Los obreros del petróleo y la nacionalización de la industria petrolera: historia oral, historia oficial y sus límites. Secuencia, v. 0, n. 13, 174-187. https://doi.org/10.18234/secuencia.v0i13.249

Organización para la Cooperación y el Desarrollo Económico - OCDE. (2020). Revenue Statistics OECD countries: Comparative tables. $\underline{U R L}$

Padilla, J.; Wood, D. (2018). El nuevo modelo mexicano de hidrocarburos: una evaluación crítica cuatro años después. Wilson Center México Institute. URL

PEMEX. (2018). Anuario estadístico. $\underline{\text { URL }}$

PEMEX. (2020). Balance primario y balance financiero de Petróleos Mexicanos y sus Organismos Subsidiarios con inversión PIDIREGAS. $\underline{\text { URL }}$

Ramones Fernández, F. (2014, 8 de abril). ¿En qué consiste la Ronda Cero? Centro de Investigación Económica y Presupuestaria. $\underline{\text { URL }}$

Reyes Tépach, M. (2008). La construcción de la infraestructura productiva en PEMEX a través de la inversión pública presupuestaria y los proyectos PIDIREGAS. Cámara de Diputados, Centro de Documentación, Información y Análisis. URL

Rousseau, I. (2010). Pemex y la política petrolera: Ios retos hacia el futuro. En Méndez, J. L. (Coord.), Los grandes problemas de México. Vol. XIII (303-341). El Colegio de México. https://2010.colmex.mx/16tomos/XIII.pdf

Rousseau, I. (2017). Tribulaciones de dos empresas petroleras estatales, 1900-2014: (Trayectorias comparadas de Pemex y PdVSA). Colegio de México.

Secretaria de Hacienda y Crédito Público (2016). Proyectos de Infraestructura Productiva de Largo Plazo (Pidiregas). URL

Solís, A. (2019, 01 de noviembre) Deuda de Pemex creció 146\% con Peña Nieto: ASF. Forbes México. $\underline{U R L}$

Sorin, B. (2019). Conventional Theory's Relevance: Evidence from Japan. Studies in Business and Economics, v. 14, n. 3, 50-59. https://doi.org/10.2478/sbe-2019-0042

Sovilla, B.; Saragos López A.; Morales Sánchez E. (2018). Contradicciones de la descentralización fiscal en México: el caso de Chiapas. Gestión y Política Pública, v. 27, n. 2. URL

Sovilla, B. (2018). Increasing the Minimum Wage with the State as Employer of Last Resort: A "predistribution" Proposal for Mexico. International Journal of Political Economy, v. 47, n. 3-4, 330-351. https://doi.org/10.1080/08911916.2018.1517463

Stiglitz, J. E. (2000). La Economía del Sector Público (3 ed.). Antoni Bosch, editor. 
La reforma energética y el problema petrolero en México

Tec Beltrán, I. L. (2018). La reforma energética: entorno macroeconómico y rentabilidad petrolera en los proyectos de exploración y producción (Trabajo de grado). $\underline{\mathrm{URL}}$

Tello Marcías, C. (2015). Sobre la baja y estable carga fiscal en México. CEPAL. URL

Tiebout, C. M. (1956). A Pure Theory of Local Expenditures. Journal of Political Economy, v. 64, n. 5, 416-424. https://doi.org/10.1086/257839

Vidal, G. (2017, 13 de enero). Pemex, comercio exterior, petróleo y gasolinas: malas noticias, El Universal. URL

Wood D.; Martin J. (2018). Cambios de paradigma y conflictos políticos: la historia de la segunda revolución energética de México. En Wood, D. (Ed). La Nueva Reforma Energética de México. Wilson Center México Institute. $\underline{U R L}$ 